DOE/ER/ $60648--3$

DE91 007876

ANNUAL TECHNICAL PROGRESS REPORT

\title{
STUDIES OF THE FORMATION, CHEMICAL REACTIVITY, AND PROPERTIES OF SMALL CLUSTERS: APPLICATION TO AN UNDERSTANDING OF AEROSOL FORMATION AND HETEROGENEOUS CHEMISTRY
}

Grant No. DE.FG02-88ER60648

For Grant Period March 1989 to March 1990

\author{
A. W. Castleman, Jr. \\ Department of Chemistry \\ The Pennsylvania State University \\ University Park, PA 16802
}

\section{DISCLAIMER}

This report was prepared as an account of work sponsored by an agency of the United States Neither the United States Government nor any agency thereof, nor any of their Government. Neither the United States Government nor assumes any legal liability or responsiemployees, makes any warranty, express or implied, or assumes any legal latility or responst bility for the accuracy, completeness, or usefulness of any information, apparatus, product, or process disclosed, or represents that its use would not inforice service by trade name, trademark, ence herein to any specific commercial product, process, or service by trade natse, tradent, recommanufacturer, or otherwise does not necessarily constitute or mony agency thereof. The views mendation, or favoring by the United States Government or any agency eflect those of the and opinions of authors expressed herein do not

United States Government or any agency thereof. 
TABLE OF CONTENTS

Page

I. INTRODUCTION ........................ . . . 1

A. Very Brief Listing of Some Important Accomplishments

During the Grant Period. . . . . . . . . . . . . . . . 2

B. Overview of Accomplishments During the Grant Period

Which Demonstrate Background and Expertise in

Cluster Research . . . . . . . . . . . . . . . 5

1. Studies Devoted to Elucidating Heterogeneous

Chemistry Related to Clusters and Aerosols . . . . 5

2. Cluster Reactions and Thermochemistry. . . . . . 15

II. PUblicAtions . . . . . . . . . . . . . . . . 41

III. BIBLIOGRAPHY . . . . . . . . . . . . . . . 46 


\section{INTRODUCTION}

For the last two and one-half years we have had a program under way to provide basic fundamental information needed to quantify the behavior of pollutants and radionuclides associated with advanced energy activities. Considerable emphasis was placed on investigating the influence of light on matter, and other studies dealt with mechanisms of heterogeneous reactions. The objective during the first two years was to investigate basic mechanisms of processes that could be of atmospheric/environmental importance and also included studies on non-atmospheric species which would serve to lay the foundation for unraveling the fundamental mechanisms of such reactions that may be influenced by heterogeneous media. In terms of atmospheric sciences, this included both ionic "solution clusters" which typify the situation existing in the aqueous/organic phases surrounding some aerosol particle surfaces. In other cases, the work dealt with identifying how electronic states evolve for metal on metal oxide (aerosol) surfaces that may potentially influence conversion processes.

During the course of these studies we found that our approach and results also enable the basic mechanisms of reactions in condensed systems to be unraveled, and we became interested in a number of potentially important processes which bear on problems in radiation biology. Hence, during the last twelve months we have begun to explore phenomena in these areas, too. In particular, we have commenced preliminary studies to begin to also provide critical information on reactions of molecules with various functional groups that simulate biological systems as they proceed in either the ionizing track of radiation or following energy transfer processes after the initial ionizing event. Utilizing molecular beams and fast-flow reaction devices, coupled with laser spectroscopy, we are able to investigate the site of photon absorption (chromophore) and the site of ionization, and to determine how the number and location of solute or solvent molecules attached to or bound about the site of absorption of the electromagnetic radiation, influences the ensuing reactions. 
The current overall program involves (1) studies of reactions related to formation and growth of heteromolecular clusters and their thermochemical properties, (2) studies of photoinitiated processes in clusters, (3) investigations related to heterogeneous reactions including the influence of reaction centers on the interconversion, and (4) theoretical calculations of properties, dynamics, and structure. A major thrust of the work during the past year has been devoted to a study of the role of ionization and the presence of ions on reactions and energetics. During the past few months, particular attention has been paid is systems having varying proton affinities. From the data, we can determine the influence of these values on the nature of the reactions and ascertain the ultimate chemical nature of the ionization center formed as a result of the reactions.

This program commenced March 1, 1988. During the last 30 months, we have submitted and or published in the refereed open literature 65 papers, 37 of which have been sponsored by this DOE grant. Additionally, 53 presentations of the findings have been made at scientific conferences and at invited talks and seminars. (In the following, where reference is made to one of our papers listed in Section II, it is designated by II followed by our publication number).

\section{A. Very Brief Listing of Some Important Accomplishments During the Grant Period}

In the last year or two, we have had a number of notable successes tha. have enabled us to accomplish some of the objectives set forth above.

a) In a comprehensive investigation of the reactions of various functional groups in organic molecules following photon absorption, we uncovered new findings about the nature of the complexes involved, the effects due to the presence of solvents and solutes, and related energy transfer mechanisms following the ionization processes (II-227,261,285,295,296,304). For example, we identified the major mechanisms emanating from $\mathrm{OH}$ and $\mathrm{CH}_{3}$ groups by studying reactions of alcohol clusters following ionization. A very specific dehydration mechanism was found which depends in a dramatic way on the degree of solvation of the complexes. The formation of protonated 
ethers was observed which bears directly on analogous reactions which take place in liquids. In another example, there has been a long-standing disagreement and anomaly in the literature concerning reactions of certain ionized complexes having $\mathrm{C}=0$ groups. Through a careful study of reactions following the ionization of acetone complexes, at differing degrees of complex formation along with water, we were able to unravel a rather interesting and complex mechanism involved for this functional group. In these studies we clearly demonstrated the influence of the presence of solvents/solutes on the nature of the reaction and clarified the mechanisms involved in this rather important reaction. We have investigated similar reactions involving $\mathrm{OH}, \mathrm{CHO}$ and proton transfer reactions. More details are given in Section II.B as well as the references listed above.

b) During the last year, we have had a major breakthrough in our laboratory which now enables us to produce large clusters under well-defined thermal conditions and to quantitatively investigate the reaction rates involving them (II-301). This puts us in the position of being able to directly determine the rates of reactions as influenced by solvation phenomena and we have already conducted some interesting measurements for large hydrates of $\mathrm{O}^{-}, \mathrm{OH}^{-}$, and $\mathrm{O}_{3}{ }^{-}$reacting with various molecules including acetonitrile and $\mathrm{CO}_{2}$. The work enabled a quantification of the reaction rate of anions (and cations) including a determination of the influence of degree of aggregation on mechanism shifts from association to switching reactions. This new advance paves the way for a number of significant studies related to condensed phase reaction phenomena. Recently we have also made interesting new findings concerning the role of rotational tunneling in energy transfer and concomitant processes of dissociation (II-269), the influence of metal ion centers on reactions (II-249,260), and the influence of bonding on the structure and formation of complexes (II-296,304).

c) A second exciting recent advance in our laboratory is the development of a new method for deducing bond energies of comparatively large cluster systems, a technique which we have also extended to mixed clusters that were otherwise very difficult to investigate. It involves using a modification of the reflectron technique and enables quantification of energy transfer and disposal 
following multiphoton ionization and ensuing reactions. Data were acquired on this, and the general mechanisms following photoabsorption in clusters was determined for the following: $\left(\mathrm{NH}_{3}\right)_{n} \mathrm{H}^{+*}$, $\left(\mathrm{CH}_{3} \mathrm{COCH}_{3}\right)_{\mathrm{n}} \mathrm{H}^{+}, \mathrm{Kr}_{\mathrm{n}}{ }^{+}, \mathrm{Ar}_{\mathrm{n}}{ }^{+}(\mathrm{II}-272,275,281,288)$. This new work, which is based on some theoretical studies by Klots at Oak Ridge, now enables us to investigate concomitant processes of energy transfer, reaction dynamics, and most importantly to, at the same time, deduce new thermochemical information for a cluster size range that has heretofore been impossible to investigate by any of the currently existing techniques available in the literature.

d) Our work on ion-cluster thermochemistry, in conjunction with earlier theoretical studies performed in our group, now enable us to determine liquid phase ion solvation values through therrnochemical measurements of gas-phase ion-molecule complexes "This major advance allows a determination of the bonding and energetics of solvation complexes in the liquid phase through gas phase measurements. Recent findings have led to new knowledge on the nature of $\mathrm{PO}_{3}{ }^{\circ}, \mathrm{a}$ biologically important ion, in the solution phase (II-274).

We also developed a method of deducing the bonding location of protons in the condensed phase, and the structure of solvation complexes through studies of dissociation dynamics, thermochemistry and magic numbers (II-296,304,305). We focused on a number of ionic systems comprised of the following species: $\mathrm{H}^{+}, \mathrm{CH}_{3} \mathrm{CO}^{+}, \mathrm{NH}_{3}, \mathrm{H}_{2} \mathrm{O},\left(\mathrm{C}_{2} \mathrm{H}_{5}\right)_{3} \mathrm{~N}, \mathrm{CH}_{3} \mathrm{OCH}_{3}$. Additionally, we obtained the first direct experimental evidence for isomeric structures in cluster ions (II-295) involving the system: $\mathrm{H}^{+} / \mathrm{NH}_{3} /\left(\mathrm{C}_{2} \mathrm{H}_{5}\right)_{3} \mathrm{~N}$.

e) In terms of spectroscopic studies, we uncovered and quantified a new mechanism of intracluster delayed electron transfer reactions involving Rydberg states. The phenomena was established for the systems paraxylene/ $\mathrm{NH}_{3} /$ trimethyl amine. We also developed a new method, cluster-ion-dip spectroscopy (II-289), which enables measurements of the ground state spectroscopy of mass selected cluster ions. The technique was directed to studies of ammonia and argon bound to paraxylene as a test system. During the course of the work, we established that structural 
rearrangements occur in clusters at specific degrees of aggregation. This was accomplished using two-color resonant enhanced multiphoton ionization. Finally, we constructed and put into operation a femtosecond laser system for use in the newly proposed work.

\section{B. Overview of Accomplishments During the Grant Period Which Demonstrate Background and Expertise in Cluster Research}

Our recent work dealing with cluster spectroscopy and dynamics of reactions has been conducted along several basic lines: (1) Studies of shifts in cluster electronic states due to solvation, including work on the influence of solvation on variations in work functions, and the "surface-cluster" analogy; (2) Investigations of photoinitiated cluster reactions, including ion-molecule half-reactions, and electron-transfer reactions; (3) Studies of the dynamics of cluster reactions and dissociation; and (4) Investigations of bonding in clusters.

\section{Studies Devoted to Elucidating Heterogeneous Chemistry Related to Clusters and Aerosols}

In view of the potential importance of het seneous processes to the chemistry of atmospheric pollutants, and the lack of knowledge concerning the basic mechanisms involved, considerable attention has been devoted to this subject in our laboratory. The surface-cluster analogy is being explored and is proving to be very useful in this regard.

\section{a. Cluster Spectroscopy}

\section{(i) Cluster Ion-Dip Spectroscopy: Probing the Ground Electronic States}

We have demonstrated for the first time the feasibility of using ion dip spectroscopy for studying molecular clusters (60). IDS is essentia'ly an optical-optical double resonance technique (see Figure 1). One (or more) pump photon(s) resonantly excites the chromophore into a real ("source") state that is more than half the energy of the ionization potential (IP). The probe (or "dump") photon energy is adjusted such that the sum of the pump and dump photon energies 
exceeds the IP of the system, leading to two-color ionization. Thus, a steady ion current is produced. The double resonance condition is met when the dump photon is in resonance with vibrational levels in the ground state manifold via stimulated emission pumping .

A dip in the two-color ion current will result when the rate of stimulated emission pumping is greater than the rate of ionization from the source state. This will be possible only when the pump minus the dump energy $\left(\omega_{1}-\omega_{2}\right)$ is in resonance with a real vibrational state in the ground state manifold. In general, there will be a steady-state condition between stimulated emission and up-pumping for the state populated by stimulated emission. However, if this state is strongly coupled to other states, then the depopulation of the electronically excited state can be further enlanced.

Because clustering ligands provide an in-situ bath for the non-radiative relaxation of a chromophore, including dissociation of the weak chromophore ligand bond, IDS appears to be ideal in probing the energetics and dynamics of a chromophore versus its degree of solvation. Toward this goal, we have advanced the optical pumping scheme used by Suzuki in their aniline studies (18) using our TOFMS for cluster ion detection to study the ground state vibrational manifold of the jet-cooled van der Waals cluster, phenylacetylene- $\mathrm{NH}_{3}$ in the energy range of $960-1044 \mathrm{~cm}^{-1}$, as well as that of phenylacetylene (PA) in the range of $900-1100 \mathrm{~cm}^{-1}$. Because ionization is taking place in the interaction region of the TOFMS, the process is also mass selective. Therefore, information on the ground state manifold of one species in the jet-cooled beam can be separated cleanly from other clusters.

The ion dip spectrum of phenylacetylene at 1000 torr stagnation pressure and $1.5 \mathrm{~cm}^{-1}$ resolution is presented in Figure 2a. The $\mathrm{x}$-axis is the energy above the vibrationless ground state, namely the difference $\left(\omega_{1}-\omega_{2}\right)$ between the pump and dump photons. All wavelengths have been corrected to vacuum. The $\mathrm{PA}^{+}$scan was obtained by setting the excitation laser, $\omega_{1}$ to $274.866 \mathrm{~nm}$ $\left(36383.0 \mathrm{~cm}^{-1}\right)$, which corresponds to the $35^{1}{ }_{0}$ electronic excitation. The dump laser was scanned 
over the region leading to stimulated emission to map out the region from 900 to $1100 \mathrm{~cm}^{-1}$ in the ground state of $\mathrm{PA}^{+}$. The spectrum is a result of monitoring the ion current at the $\mathrm{PA}^{+}$mass channel in the TOFMS. The strongest features at $976,1000,1026$, and $1037 \mathrm{~cm}^{-1}$. The maximum dip intensity, as determined from the ratio of the dip to the ion current before the dip feature, is less than $40 \%$.

The PA- $\mathrm{NH}_{3}{ }^{+}$spectrum, taken at $1.1 \mathrm{~cm}^{-1}$ resolution, is shown in Figure $2 \mathrm{~b}$. The cluster spectrum was obtained by setting $\omega_{1}=36298.5 \mathrm{~cm}^{-1}$, which is the $35_{0}^{1}$ transition of the $\mathrm{PA}-\mathrm{NH}_{3}^{+}$ van der Waals cluster, red-shifted by $84.5 \mathrm{~cm}^{1}$. The dump laser was adjusted to scan over the same energy range as in the PA case $\left(\omega_{1}-\omega_{2} \rightarrow 900-1100 \mathrm{~cm}^{-1}\right)$. At this resolution, the dips at $1000 \mathrm{~cm}^{-1}$ and $1026 \mathrm{~cm}^{-1}$ appear to match those observed in PA. However, a broad dip signal is seen at 976 $\mathrm{cm}^{-1}$. The depth of the dips is similar to that of the PA Ion Dip spectrum (less than $50 \%$ of the signal), which indicates that dissociation does not make a dominant contribution to the SEP kinetics. This is because the dissociation of the cluster on the timescale of the dump step would lead to collapse of the population in the dump state. This in turn would drain off more prpulation in the $S_{1}$ state than would be the case if dissociation were not a factor. In general, dissociative processes should lead to dips > 50\% (depending on the intensity of the dump laser) whereas non-dissociative pathways are inherently limited to dips $\leq 50 \%$. Thus, the dissociation of the complex is not the main channel for relaxation of the down pumped population of the vdW cluster.

At the highest resolution of $0.3 \mathrm{~cm}^{-1}$, the $1026 \mathrm{~cm}^{-1}$ band for PA remains unresolved. The scan of the PA- $\mathrm{NH}_{3} 1026 \mathrm{~cm}^{-1}$ band reveals a reproducible $2.3 \mathrm{~cm}^{-1}$ red shin of the $1026 \mathrm{~cm}^{-1}$ band to $1024.4 \mathrm{~cm}^{-1}$. However, there is a small peak still at $1026 \mathrm{~cm}^{-1}$. In the $\mathrm{PA}-\mathrm{NH}_{3}$ complex, the $\mathrm{NH}_{3}$ group is assumed to be centered over the aromatic ring, with one hydrogen pointing into the center of the phenyl ring. Thus, the $\mathrm{NH}_{3} \mathrm{vdW}$ bond would be expected to influence the phenyl ring vibrations most strongly. We might therefore expect that the $10_{0}{ }^{1}$ band would exhibit a shift, and the $35_{0}{ }^{2}$ band would appear unperturbed, within our spectral resolution. The observation that the 
most intense band undergoes a shift is consistent with this interpretation.

This study has shown that the perturbation exerted by $\mathrm{NH}_{3}$ on the normal modes of PA is highly mode specific. No perturbations are observed for vibrations removed from the aromatic ring. Quite the contrary is seen for those vibrational modes that would logically feel the greatest perturbation due to clustering. Surprisingly, there appear to be no van der Waals states that lead to predissociation of the PA- $\mathrm{NH}_{3}$ complex in the $960-1044 \mathrm{~cm}^{-1}$ energy range of the $\mathrm{PA}-\mathrm{NH}_{3} \mathrm{~S}_{0}$ state. We are currently working to expand these findings to different vibrational modes of the $\mathrm{PA}-\mathrm{NH}_{3}$ cluster, higher clusters of PA- $\left(\mathrm{NH}_{3}\right)_{n}$, as well as other van der Waals clusters of PA. CIDS should prove quite useful in probing ground state vibrational energetics and dynamical processes in clusters with high resolution, sensitivity, and mass selectivity.

\section{(ii) Spectroscopy at a Cluster Surface}

Based on previous work in our laboratory, information of the spectral shifts of PA clustered to various molecules and atoms is available $(19,20)$. New data on the spectroscopy of phenylacetylene (FA) attached to ammonia clusters with emphasis on larger clusters, namely those clusters of PA attached to more than one solvent molecule, were obtained (II-254,257). The experiments reported were performed using a newly constructed laser based time-of-flight (TOF) mass spectrometer. Ionization is done via one-color two-photon REMPI of the $S_{1}-S_{0}$ transition in PA $\left({ }^{1} B_{2}\left({ }^{1} L_{b}\right)-{ }^{1} A_{1}\left({ }^{1} A\right)\right)$. The first excited state $S_{1}$, of PA is favorably near the mid-point of the ionization potential, leaving the parent cluster ions with only a small excess energy of $=600 \mathrm{~cm}^{-1}$.

A unique aspect of our more recent work is a study of the spectroscopic shifts which arise upon the attachment of PA to a preformed ammonia cluster "surface". Data on clusters produced by a conventional coexpansion method were obtained to provide a concrasting comparison to the attachment results. By examining the spectroscopy of a chromophore lying on the surface of a cluster the perturbations in the spcctra should arise from the clusier acting as a unit. The 
coexpansion experiments show a red spectral shift of $-80 \mathrm{~cm}^{-1}$ for $\mathrm{PA}\left(\mathrm{NH}_{3}\right)$, which is found to saturate at $\sim-50 \mathrm{~cm}^{-1}$ for clusters $\mathrm{PA}\left(\mathrm{NH}_{3}\right)_{\mathrm{n}}$ where $\mathrm{n}=2-7$. By contrast, clusters made by attaching a PA molecule to an already formed $\left(\mathrm{NH}_{3}\right)_{\mathbf{n}}$ cluster exhibit a spectral shift of approximately -80 $\mathrm{cm}^{-1}$ for $\mathrm{PA}\left(\mathrm{NH}_{3}\right)_{\mathrm{n}}$ clusters where $\mathrm{n}=1$, and values similar to the coexpansion experiments for $\mathrm{n}=2-4$. However, they display a much different and gradually increasing shift from $-110 \mathrm{~cm}^{-1}$ to $-150 \mathrm{~cm}^{-1}$ for $\mathrm{n}=5$ through 16 . See Figure 3. The difference between these two experiments is related to the different interactions present in nucleated $\mathrm{PA}\left(\mathrm{NH}_{3}\right)_{\mathrm{n}}$ clusters versus those in complexes in which a PA is attached to the surface of a cluster.

By attaching a PA molecule to an already formed ammonia cluster the interaction is evidently between an $\left(\mathrm{NH}_{3}\right)_{\mathfrak{n}}$ cluster and the $\pi$ system of the attached PA. Changes in these spectra should be due to the large polarizability of an $\left(\mathrm{NH}_{3}\right)_{\mathrm{n}}$ cluster and its effect on the electronic structure of PA. Despite the relatively large size of these clusters, the observed $150 \mathrm{cin}^{-1}$ red spectral shift of $\mathrm{PA}\left(\mathrm{NH}_{3}\right)_{16}$ is about half of the 245 to $300 \mathrm{~cm}^{-1}$ red spectral shifts observed for cryogenic solutions of benzene in nitrogen, carbon monoxide, carbon tetrafluoride, ethane, and propane (21). These experiments clearly demonstrate the exciting prospects of cluster spectroscopy as a way of probing molecular interactions at both cluster surfaces, and for solvated complexes.

\section{b. Reactions of Metal Clusters}

Currently, there is considerable interest in the chemistry of heavy metals. Additionally, the role of alkali metals as catalyst promoters is known, but not fully understood. We have conducted studies on these topics in our laboratory. In these studies, intermetallic clusters of bismuth/sodium, bismuth/potassium, and tellurium/sodium were produced, and various reactions were studied (II-267,284). The observed mass spectral abundances of bismuth-alkali cluster ions provides conclusive evidence for the existence of gas phase anionic Zintl ions of bismuth, having analogy to 
particularly stable homopolyatomic anionic clusters of bismuth known in the solution and the solid state. Laser-ionization time-of-flight mass spectra of intermetallic bisinuth/sodium clusters, produced in a gas aggregation source, exhibit "magic numbers" for all intermetallic cluster ions possessing stoichiometries consistent with known bismuth Zintl structures, with the sole exception of $\mathrm{Bi}_{2}{ }^{4-}$. Instead, $\mathrm{Bi}_{2} \mathrm{Na}^{3+}$, which is isoelectronic with $\mathrm{Bi}_{2}{ }^{2 *}$, is observed, suggesting the electronic octet rule dominates the stability of this small cluster. The expected Zintl species $\mathrm{Bi}_{7}{ }^{3-}$ is very prominent in the mass spectra. Additionally, clusters corresponding to $\mathrm{Bi}_{4}^{4-}, \mathrm{Bi}_{6}{ }^{4-}, \mathrm{Bi}_{8}{ }^{4-}, \mathrm{Bi}_{9}{ }^{5-}$, and $\mathrm{Bi}_{14}{ }^{6-}$ are exceptionally abundant, and it is expected some of these may exist in solution. We conclude that the sodium atoms merely donate electron density to the underlying anionic bismuth Zintl ion, which determines the stabilities of these clusters.

While various electron counting schemes have been employed to rationalize the stabilities of particular intermetallic ions, the large number of valence electrons for bismuth causes problems for such interpretations. Reactions of these bismuth-alkali clusters with closed-shell HX acids provides further insight into the structures, formation, and stabilities of these intermetallic species. In our experiments, $\mathrm{HCl}$ and $\mathrm{HI}$ are found to quantitatively strip $\mathrm{Bi}_{x} \mathrm{Na}_{y}$ and $\mathrm{Bi}_{\mathbf{x}} \mathrm{K}_{\mathbf{y}}$ respectively of their alkali component, leaving bare bismuth clusters as the only bismuth-containing species detected. Product bismuth clusters exhibit the same distribution observed when pure bismutin is evaporated in the source. Though evaporated simultaneously from the same crucible, this suggests alkali atoms condense onto existing bismuth clusters and have negligible effect on their formation and consequent distribution. The indistinguishability of reacted and pure bismuth cluster distributions further argues against the simple replacement of alkali atoms with hydrogen in these reactions. This is considered further evidence that the alkali atoms are external to the stable bismuth Zintl anionic structures. Reactivities of $\mathrm{Bi}_{x} \mathrm{Na}_{y}$ clusters with $\mathrm{HCl}$ range between $3 \times 10^{-13}$ for $\mathrm{Bi}_{4} \mathrm{Na}$, to greater than $4 \times 10^{-11}$ for clusters possessing large numbers of alkali atoms. Bare bismuth clusters are observed in separate experiments to react significantly more slowly with rates 
of $1-9 \times 10^{-14}$, and exhibit little variation of reactivity with size. The bismuth clusters may thus be considered a relatively inert substrate upon which the alkali-overlayer reacts.

Currently there is consicierable interest in single component metal clusters, both to elucidate their different behavior arising from metal-metal interactions and their potential role as sites of catalytic activity. A comparison of cluster size distributions for one- and two-photon ionization conditions have suggested fragmentation of lead clusters as well as mixed clusters comprised of $\mathrm{Pb}$ and $\mathrm{Sb}$ (II-255). More recently, a systematic study of the influence of laser fluence on the preferential fragmentation of $\mathrm{Pb}$ clusters following MPI at $308 \mathrm{~nm}$ has been undertaken. In these experiments, lead clusters are formed by evaporation of $99.9995 \%$ pure metal in argon employing a gas aggregation technique in a fast-flow reactor. A fraction of the flow is sampled through a small orifice and the resulting beam intersected by a pulsed excimer laser operating at $308 \mathrm{~nm}$. The photoions are formed in the electrostatic lens of a time-of-flight mass spectrometer and detected by a multichannel plate particle multiplier.

Based on ionization potentizls determined for lead clusters $P b_{n}(n \leq 7)$ by electron impact ionization (22), two $308 \mathrm{~nm}$ photons are required for ionization of the clusters investigated in the present study. See a typical cluster distribution in Figure 4a. Emphasis is placed on determining the extent of fragmentation at tiuences near threshoid. In order to accomplish this, cluster ion intensities are determined as a function of cluster size at different laser fluences. As shown in Figure $4 \mathrm{~b}$, at the lowest fluences needed to detect clusters $\left(2 \mathrm{~mJ} / \mathrm{cm}^{2}\right)$, the observed intensities for most cluster ions increased $5 \%$ to $25 \%$ with a $30 \%$ increase in laser fluence. Only $(\mathrm{Pb})_{12}$ decreases, and clusters 3,4 , and 6 all snow a greater than $40 \%$ increase in intensity. Based on this observation, we infer that $(\mathrm{Pb})_{1.2}$ absorbs a third photon, possibly after ionization, and fragments to ionic clusters of 3,4 ur $6 \mathrm{~Pb}$ atons. An alternative possibility is that the $\mathrm{Pb}_{12}$ cation is unstable and dissociates to the smaller cluster sizes. However, in this case no dependence on laser fluence would h.s expected 
It is also interesting that $(\mathrm{Pb})_{14}$ is entirely absent at all fluences, as reported by others $(\angle 3)$. On the other hand, $(\mathrm{Pb})_{14}$ was observed by that group at 193 and $157 \mathrm{~nm}$. Further, $(\mathrm{Pb})_{14}$ wis observed by Sattler (23) using a low energy (30 eV) electron impact ionization on clusters made in a gas aggregation source. We are thus confident that $(\mathrm{Pb})_{14}$ is indeed present in our neutral cluster distribution, despite its absence from our ion distribution. Between 7.92 and $8.05 \mathrm{eV},(\mathrm{Pb})_{14}$ either fragrnents with near unit efficiency or readily absorbs a third $4.03 \mathrm{eV}$ photon and subsequently decomposes. In light of the findings for $(\mathrm{Pb})_{12}$, we favor the latter explanation. The reflectron technique, extended in our laboratory to a study of cluster dissociation, enabled a study of the dissociation dynamics of metal clusters. In analogy to our findings for van der Waals and hydrogen bonded systems, wa find the dissociation probability in a given time window to also increase with cluster size; see Figure 5.

Techniques have recently been developed in our laboratory to investigate the rate of neutral metal cluster reactions. These are the first such data available for well defined conditions of thermalized clusters at a known pressure and temperature where possible concomitant cluster formation and growth processes are not influencing the reaction measurements. Data for reactions of $\mathrm{Pb}$ clusters with $\mathrm{NO}_{2}$ and $\mathrm{H}_{2} \mathrm{~S}$ are shown in Figures $6 \mathrm{a}$ and $6 \mathrm{~b}$. Interestingly, the rates show a dependence on cluster size and hence on the electronic/geometric structure of the clusters. Experiments are in progress to unravel the mechanisms.

Results obtained so far on tellurium and tellurium/sodium clusters are only preliminary; however, a few exciting results are apparent. The intense peak at $\mathrm{Te}_{5}{ }^{+}$as reported by Neubert (24) has been reproduced, and in addition, a large peak is observed for $\mathrm{Te}_{8}{ }^{+}$, corresponding to the well-known ring-shaped $\mathrm{Se}_{8}$. Distributions of tellurium/sodium clusters are found to possess either 
one or two sodium atoms, suggesting these form chains of tellurium, with either one or two terminal sodium atoms attached.

\section{c. The Chemistry and Structure of Metal Oxide Particles}

A primary goal of cluster research is to better understand the transition from isolated atoms and molecules to the condensed state. There is particular interest in the rate at which cluster properties approach those of bulk condensed matter, and the amount of cluster specificity shown during the transition. One important source of information has been mass spectral abundance patterns, where the relative intensities of cluster peaks are interpreted as being indicative of cluster stability. In many cases the so called "magic numbers" observed have been successfully explained using eith/r electronic or structural models. Studies of metal oxides are particularly interesting because of weir presence in some aerosols and their role as catalysts.

In one phase of our study we produced $\mathrm{MgO}$ clusters in a gas aggregation source and analyzed them using laser ionization time-of-flight mass spectrometry (II-302). In support of the experiments, we also calculated the stabilities of $\mathrm{MgO}$ clusters using an ionic model which Martin (25) has employed to explain many of the features observed in the mass spectra of alkali halide clusters. Our intent is to try to infer the geometric structures of these metal nxide clusters from mass spectral abundance patterns and also explore the applicability of the Martin model to divalent metal oxide clusters which, unlike the clusters previously studied, should have a significant covalent bonding component that is not accounted for in the ionic model.

Mass spectra were obtained under different experimental conditions in order to maximize cluster intensities in different size ranges. Figure $7 \mathrm{a}$ is a mass spectrum of $(\mathrm{MgO})_{\mathrm{x}}$ and $\mathrm{Mg}_{\mathrm{x}} \mathrm{O}_{\mathrm{x}-1}$ clusters collected with conditions optinized for small clusters, and Figures $7 \mathrm{~b}$ and $7 \mathrm{c}$ are from a single mass spectrum optimized for medium and large clusters. There are many abundance maxima present in both the $(\mathrm{MgO})_{x}$ and $\mathrm{Mg}_{\mathrm{x}} \mathrm{O}_{\mathrm{x}-1}$ series, which extend up to about $\mathrm{x}=90$. These are listed in Table I along with proposed structures based on cubic geometries. 
The binding energies of neutral $(\mathrm{MgO})_{x}$ clusters were calculated using the ionic model of Martin $(25,26)$. In this model, a cluster is assumed to be composed of ionic constituents (here $\mathrm{Mg}^{+\mathbf{z}}$ and $\mathrm{O}^{-\mathrm{z}}$ ) that interact by the pairwise Born-Mayer potential

$$
V_{i j}=Z_{i} Z_{j} e^{2} / 4 \pi \epsilon_{o} R_{i j}+\lambda \exp \left(R_{i j} / \rho\right)
$$

where $Z_{i}$ and $Z_{j}$ are the charges (in units of e) on two interacting ions, e and $\epsilon_{o}$ are physical constants, $R_{\mathrm{ij}}$ is the distance between the ions, and $\rho$ and $\lambda$ are two parameters that can be obtained from the lattice constant and compressibility of the bulk. The cluster binding energy relative to the ions at infinite separation is found by summing $V_{i j}$ over all ions $(i \neq j)$. The maximum binding energy for a n-atom cluster is found by varying the ion positions until a maximum is obtained.

The mass spectral abundance maxima observed for $(\mathrm{MgO})_{\mathrm{x}}$ and $\mathrm{Mg}_{\mathrm{x}} \mathrm{O}_{\mathrm{x}-1}$ clusters $(\mathrm{x} \leq 90)$ can be explained as resulting from enhanced stabilities of high symmetry cubic structures which resemble pieces of the bulk. Similar patterns have been observed for sputtered MgO clusters (26) of small size ( $x \leq 15)$ and for numerous alkali halide systems (27). In addition, small cubic MgO crystals ( $>1000$ atoms) have been observed using microscopy.

Alkali halicie clusters can be described reasonably well using an ionic model, but it is questionable how well such a model applies to $\mathrm{MgO}$ or other oxide clusters. The primary difficulty is that these systems are not purely ionic in character, and questions arise as to the effective charges on the ions and the importance of covalent bonding contributions. The results of our theoretical calculations for assumed constituent charges of \pm 1 and \pm 2 yield very different stable geometries. The calculations using single charges yield cubic geometries and the relative stabilities of the structures are in good agreement with the mass spectral abundance patterns. By contrast, the preferred geometries of high charge clusters are open structures and the relative stabilities do not agree with experiment. 
These results indicate that $\mathrm{MgO}$ clusters develop the solid state geometry at very small cluster sizes and that a simple ionic model can be used to calculate these structures if effective charges of about \pm 1 are assumed for the constituent ions. This amount of charge is close to the value of 1.14 obtained from the dipole moment of MgO monomer, but it is far from the value of about 1.85-1.90 measured for solid MgO by X-ray analysis (28). Hence, importantly, the experimental findings provide convincing evidence that the electronic properties associated with the bulk condensed state develop only at very large cluster sizes, further demonstrating the unique aspects of clusters, fine particles, and aerosols.

We are presently developing a theoretical model which will incorporate a covalent bonding contribution in the cluster energy, and allow the ionic charge to vary with cluster size. This should allow us to make more quantitative calculations of ionic cluster properties and obtain better insight into the transition from monomer po bulk.

\section{Cluster Reactions and Thermochemistry}

The ongoing research on cluster reactions and thermochemistry pertains to both the reactions of functional groups that relates to radiation biology and the photochemistry of pollutants in aerosols.

\section{a. Studies of Bonding and Kinetic Energy Release}

Recently, we have studied the metastable dissociation dynamics of cluster ions (II-281,297) by measuring the average kinetic energy release and unimolecular dissociation rate constant during ion decomposition by using a peak shape analysis method in a TOF mass spectrometer $(3,4)$. During the decomposition of a metastable parent ion in the field-free drift region, the internal energy of the parent ion is converted to the translation energy of the daughter ion. As a result, translation energy distribution of the daughter ion is expected to be broader than that of the parent ion due to the kinetic energy release in the decomposition process. The importance of using a 
reflectron time-of-flight mass spectrometer in the studies of metastable unimolecular dissociation dynarnics is that it enables simultaneous determination of the kinetic energy release and the dissociation rate. The method is found to lead to values of high precision, which in combination with various theoretical approaches, enables a determination of cluster bond energies.

Attention was first focused on the prototypical molecule, ammonia. As seen in Figure 8, the measured averaged kinetic energy release of metastable $\left(\mathrm{NH}_{3}\right)_{n} \mathrm{H}^{+}, \mathrm{n}=4-17$, displays a maximum value of $9.5 \mathrm{meV}$ at $n=5$ and a gradual decrease to a value of $5.0 \mathrm{meV}$ for $n=17$. This finding of maximum kinetic energy release of $\left(\mathrm{NH}_{3}\right)_{5} \mathrm{H}^{+}$is consistent with the recent $\mathrm{KER}$ measurements of $\left(\mathrm{NH}_{3}\right)_{\mathrm{n}} \mathrm{H}^{+}, \mathrm{n}=2-8$, obtained with a double focusing mass spectrometry method (29). This indicates that the parent cluster ion $\left(\mathrm{NH}_{3}\right)_{5} \mathrm{H}^{+}$releases the most kinetic energy during unimolecular decomposition. A small local maximum in the average kinetic energy release is also evident at $n=12$. The measured KER values are in good agreement with those of Lifshitz et al. (29) for $n=4-6$. In the case of $n=7$ and 8 , the only other larger clusters which they studied, their values show an unexpected rise.

Employing the KER data, and using a modified QET/RRK statistical analysis $(30,31)$, binding energies for large cluster ions can be readily determined. In this method, the deduced binding energy vin? ues are scaled to match the best determined value for $\left(\mathrm{NH}_{3}\right)_{5} \mathrm{H}^{+}$in the literature $(8,9)$. The binding energies determined in the present work are in good agreement with the reported literature values for cluster ions $\left(\mathrm{Ni}_{3}\right)_{n} \mathrm{H}^{+}, \mathrm{n}=4,6$ and 7 (see Figure 9). The trend of the determined binding energies of metastable cluster ions $\left(\mathrm{NH}_{3}\right)_{n} \mathrm{H}^{+}$shows a progressive decrease from $n=4$ to 5 , displays a precipitous drop from 5 to 6 and then slowly decreases thereafter. There are hints of slightly more stable structures than neighboring ones at $n=12$ and 14 .

In our observable time window $(1-40 \mu \mathrm{s})$, the measured unimolecular dissociation rate constants of metastable cluster ions $\left(\mathrm{NH}_{3}\right)_{\mathrm{n}} \mathrm{H}^{+}$, display an appreciable dependence on cluster size, where the values rise from $3.1 \times 10^{2}$ to $1.7 \times 10^{4} \mathrm{~s}^{-1}$ as $\mathrm{n}$ increases from 4 to 18 (II-263). This 
finding is consistent with our results in the determination of binding energies of $\left(\mathrm{NH}_{3}\right)_{n} \mathrm{H}^{+}$, where clusters with lower binding energies should display larger unimolecular dissociation rates. These experimental results can be well explained with the consideration of cluster energy content and temperature (II-227).

Very recently, we explored another approach as an alternative method of determining und energies, one with even more general application. The most recent version requiring no adjustable parameters, but involves application of the evaporative ensemble method (II-297). In the newer work, a precise method wa: devised for measuring decay fractions of metastable cluster ions with corrections concerning instrumental artifacts which could arise due to different trajectories of parents and daughters. The experimental data are used to derive the Gspann parameter and heat capacity of clusters as described in Klots' evaporative ensemble model. With these two parameters and measv"ed kinetic energy release values, we applied the evaporative ensemble model to obtain binding energies of ammonia cluster ions $\left(\mathrm{NH}_{3}\right)_{n} \mathrm{H}^{+}, 4 \leq n \leq 17$. The deduced binding energy values are in very good agreement with both thermochemicai data and Engelking's modified statistival iheory (see Figure 9).

Although woth statistical theories are applicable for deriving the binding energy from kinetic energy relcase, the modified QET/RRK theory requires many parameters, such as number of active cluster modes, vibrational frequersies of each cluster mode, geometric cross section for formiry, cluster ion, etc. A greater limit. ion in its use is that it requu es some known thermochemical values in order to adjust some scaling parconeters. By contrast, the evaporative ensemble model requires only two parameters which can be ded wed from a precise measurement of decay fractions of cluster ions. Importantly, the deduced binding energies of cluster ions using the evaporative ensemble model agree very well with the reported literature values for smaller clusters.

The stucies of the metastable cluster ion dissociation dynamics by measuring the average 
kinetic energy release and unimolecular dissociation rate constant have been extended (II-304) for protonated acetone, dimethyl ether, and diethyl ether cluster ion systems. Hence, we have deduced a large body of new thermochemical data which are very useful in assessing the exothermicities of reactions and the nature of ion centers to which various ligands are bound.

\section{b. Investigations of Reactions of Functional Groups Following Ionization and Photochemical Effects}

(i). Alcohol Experiments

Clusters comprised of methanol molecules represent a promising system for exploring reactions as a function of cluster size. Reactions between methanol ions and methanol have been well explored in the gas phase by both ICR (32) and fast-flow reactor techniques (33). Alcohol ions are known to undergo a number of isomerization and dehydration reactions leading to dimethyl ether and water. Furthermore, there are ample data on reactions in the liquid phase and the gas-phase of thermochemistry of protonated systems comprised of alcohol-water mixtures to provide a basis for data interpretation $(34,35)$.

In an earlier study (36), we investigated internal ion-molecule reactions in small methanol clusters and observed that the protonated methanol dimer underwent a delayed reaction corresponding to the production of protonated dimethyl ether and the loss of an $\mathrm{H}_{2} \mathrm{O}$ molecule. No similar reaction channel was found for neighboring cluster sizes, a finding which was in accord with gas-phase ion-molecule reaction studies (32).

In a new series of experiments (II-261,262), the cluster beam was subjected to multiphoton ionization and the resulting cluster ions analyzed in a time-of-flight (TOF) mass spectrometer equipped with a reflecting electric field (reflectron). The predominant unimolecular reactions involving loss of one or more monomer units were found to exhibit no specificity with cluster size and the "splitting off" of monomer units and multiples thereof from the clusters occurs for all sizes studied. In a cluster composed of such units there are always a number of "surface" monomer-unit 
entities that can be relatively easily dissociated. In contrast, however, reactions of methanol clusters reveal a distinct dependence on degree of solvation for certain reactions of methanol clusters following multiphoton ionization. It is also not surprising that reactions requiring extensive rearrangement (the ion-rnolecular reactions) proceed only for cluster sizes where this rearrangement is expected to be facile. The first such incidence investigated by us in the methanol system involves the previously reported (36) loss of water from the protonated methanol dimer ion $\mathrm{H}^{+}\left(\mathrm{CH}_{3} \mathrm{OH}\right)_{2}$. The reaction is specific to only the aforementioned cluster size.

In addition to the evaporative loss of methanol, and the reaction of the protonated dimer which leads to the production of protonated dimethyl ether and elimination of water, several other size dependent intracluster reaction pathways have been revealed in the present study. In the case of intermediate and larger clusters, $\left(\mathrm{CH}_{3}\right)_{2} \mathrm{O}$ is lost while $\mathrm{H}_{2} \mathrm{O}$ is retained by the cluster. For clusters comprised of 4 to 9 methanol molecules, $\left(\mathrm{CH}_{3}\right)_{2} \mathrm{O}$ elimination is observed to occur over the time window of 1 to $15 \mu \mathrm{sec}$ after ionization as evidenced by the observed mass loss during flight through the field-free region to the reflectron.

For the larger clusters, the appearance of $\mathrm{H}^{+}\left(\mathrm{H}_{2} \mathrm{O}\right)\left(\mathrm{CH}_{3} \mathrm{OH}\right)_{n}$ in the conventional TOF mass spectrum implies that the elimination takes place well before the ions enter the field-free region. The loss of $\left(\mathrm{CH}_{3}\right)_{2} \mathrm{O}$ occurs on a rapid time scale (in the ion lens) creating mixed clusters of form $\mathrm{H}^{+} \cdot \mathrm{H}_{2} \mathrm{O}\left(\mathrm{CH}_{3} \mathrm{OH}\right)_{n}$ where $\mathrm{n}=7$ or greater (b peaks, Figure 10). An ion with the nuss of $\mathrm{H}^{+}\left(\mathrm{CH}_{3} \mathrm{OH}\right)_{7}$ requires about $1.3 \mu \mathrm{sec}$ to exit the acceleration field and enter the field-free region under the experimental conditions employed in the experiments.

The results can be explained by estimates that ether is only slightly more strongly bound than methanol to protonated methanol clusters of size $n=4$, and the solvation may be about thermoneutral at $n=5$. Beyond this size the solvation of $\mathrm{CH}_{3} \mathrm{OH}$ may be preferential. Based on high pressure mass spectrometric measurements of mixed protonated alcohol-water clusters comprised of all combinations up to a total of 6 molecuies, Kebarle and coworkers (37) conclude 
that methanol is preferentially solvated by the proton in $\mathrm{sm}^{\prime} \mathrm{i}$ ion clusters, while in ones with more than a total of 9 molecules, interaction with water would dominate over than of methanol.

During the course of this study, the question arose as to whether the solvation driven reactions observed in this study resulted from transient dynamical events following multiphoton ionization of the neutral clusters. In order to further elucidate the nature of the reactions, we conducted similar ones under thermal conditions in the fast-flow reactor. The newly developed technique for producing large water clusters was applied to the alcohol system with good success. The new findings confirm that the above mentioned reaction involves mechanisms operating under well-defined thermal conditions.

\section{(ii). Multiphoton Ionization Study of Acetone Clusters and Unimolecular Decompositions of Solvated Acetone Cluster Ions}

Reactions of ionized acetone provide valuable insight into the reactivity of various molecular functional groups. Experiments of ion-molecule reactions of gaseous acetone (T) (38-42) showed that $(\mathrm{T})_{\mathrm{m}} \cdot \mathrm{H}^{+},(\mathrm{T})_{\mathrm{m}} \cdot \mathrm{CH}_{3}{ }^{+}$, and $(\mathrm{T})_{\mathrm{m}-1} \cdot \mathrm{CH}_{3} \mathrm{CO}^{+}, \mathrm{m}=1-4$, are the major secondary cluster ions. These species are the product ions resulting from the reactions between the primary ions, $\mathrm{CH}_{3} \mathrm{CO}^{+}, \mathrm{CH}_{3} \mathrm{COCH}_{3}{ }^{+}, \mathrm{CH}_{3}{ }^{+}$and the gaseous acetone molecule. Stace and Shukla (22) investigated the cluster ions of acetone systems by ionizing the neutral clusters and found no evidence of ions corresponding to $\mathrm{C}_{6} \mathrm{H}_{11} \mathrm{O}^{+}$or $\left(\mathrm{T}_{\mathrm{n}} \cdot \mathrm{C}_{6} \mathrm{H}_{11} \mathrm{O}^{+}\right.$. They suggested that this is due to different routes leading to the formation of their precursor ions, $\mathrm{T}_{\mathrm{n}} \cdot \mathrm{H}^{+}$.

In our present investigation, experiments were undertaken to study the stabilities and fragmentation branching ratios of cluster ions. The observed major cluster ions found after the prompt fragmentation following ionization are: (i) $(\mathrm{T})_{\mathrm{m}} \cdot \mathrm{H}^{+}, \mathrm{m}=1-15$, (ii) $(\mathrm{T})_{\mathrm{m}} \cdot \mathrm{CH}_{3} \mathrm{CO}^{+}$, and (iii) $(\mathrm{T})_{\mathrm{m}} \cdot \mathrm{CH}_{3}{ }^{+}, \mathrm{m}=1-10$. Under collision-free conditions all three types of cluster ions undergo unimolecular decomposition, each boiling off one acetone molecule.

The acetyl cation, $\mathrm{CH}_{3} \mathrm{CO}^{+}$, being the most stable one among at least four stable structures 
of $\mathrm{C}_{2} \mathrm{H}_{3} \mathrm{O}^{+}$ions $(44,45)$, is the most abundant fragment species from the ionized acetone monomer. However, the solvated ions, $(T)_{m} \cdot \mathrm{C}_{2} \mathrm{H}_{3} \mathrm{O}^{+}, \mathrm{m}=1-17$, are also present in a significant amount. Their intensities are slightly lower than those of protonated species of the same number of solvent molecules for $m=1-10$. Contrarily, for $m>10$, the solvated acetyl species are more abundant than the protonated species.

The observed major cluster ions resulting from prompt fragmentation following ionizaion are $\left[\left(\mathrm{CH}_{3}\right)_{2} \mathrm{CO}\right]_{\mathrm{m}} \cdot \mathrm{H}^{+}, \mathrm{m}=1-15,\left[\left(\mathrm{CH}_{3}\right)_{2} \mathrm{CO}\right]_{\mathrm{m}} \cdot \mathrm{C}_{2} \mathrm{H}_{3} \mathrm{O}^{+}, \mathrm{m=1}=17$, and $\left[\left(\mathrm{CH}_{3}\right)_{2} \mathrm{CO}\right]_{\mathrm{m}} \cdot \mathrm{CH}_{3}{ }^{+}$, $m=1-10$. In a time window of a few tens of microseconds, all these three classes of cluster ions unimolecularly decompose, losing only one acetone monomer. Interestingly, a reaction corresponding to the dehydration of $\left[\left(\mathrm{CH}_{3}\right)_{2} \mathrm{CO}\right]_{\mathrm{m}} \cdot \mathrm{H}^{+}$and leading to the production of $\left[\left(\mathrm{CH}_{3}\right)_{2} \mathrm{CO}\right]_{m-2} \cdot \mathrm{C}_{6} \mathrm{H}_{11} \mathrm{O}^{+}$is observed for $\mathrm{m}=2-6$. The most striking finding of the present study is that the presence of water molecules in a cluster suppresses the dehydration reaction. This finding clarifies the discrepancy between earlier studies reported in the literature and, most importantly, provides further evidence for the influence of a solvent on ion reactions in clusters, and ion-molecule reactions in general.

One can readily identify the ion peaks at masses 157 and 215 corresponding to the $(\mathrm{T})_{\mathrm{m}-2^{\circ}} \mathrm{C}_{6} \mathrm{H}_{11} \mathrm{O}^{+} \mathrm{m} \geq 2$, ions, as ones clearly originating from the direct elimination of water molecules from the $(T)_{m} \cdot H^{+}$via the reaction:

$$
(\mathrm{T})_{\mathrm{m}} \cdot \mathrm{H}^{+} \rightarrow(\mathrm{T})_{\mathrm{m} \cdot 2^{2}} \cdot \mathrm{C}_{6} \mathrm{H}_{11} \mathrm{O}^{+}+\mathrm{H}_{2} \mathrm{O}
$$

Experiments were conducted to study the influence of the presence of water in the cluster on the above dehydration reaction. In the case where $0.7 \%$ water is present in the acetone sample, the ion peaks corresponding to the $(\mathrm{T})_{\mathrm{m}-2^{*}} \mathrm{C}_{6} \mathrm{H}_{11} \mathrm{O}^{+}, \mathrm{m}=3$ and 4 (masses 157 and 215) and $\left\{(\mathrm{T})_{3} \cdot\left(\mathrm{H}_{2} \mathrm{O}\right)\right\} \mathrm{H}^{+}$ion (mass 193$)$ are evident. In the case where water content in the acetone sample 
is $1.0 \%$. Interestingly, the peak corresponding to the $\left\{\left(\mathrm{T}_{3} \cdot\left(\mathrm{H}_{2} \mathrm{O}\right)\right\} \mathrm{H}^{+}\right.$ion (mass 193) is evident whereas those corrasponding to the $(\mathrm{T})_{\mathrm{m}-2^{\circ}} \mathrm{C}_{6} \mathrm{H}_{11} \mathrm{O}^{+}$ions are not seen (no peaks appear at either mass 157 or mass 215). The findings establish that the presence of water inhibits the dehydration mechanism of $(\mathrm{T})_{\mathrm{m}} \cdot \mathrm{H}^{+}$cluster ions even through the rearrangement mechanism shown in Figure 11.

Reaction (2) has been reported by many researchers (40-42) in the studies of ion-molecule reactions of the gas phase acetone system. On the contrary, Stace and Shukla (43) did not observe this reaction in studies where the neutral clusters of acetone were ionized by electron impact. They suggested a possible explanation that the structures of the precursor ion $(T)_{m} \cdot \mathrm{H}^{+}$are different in these two different experiments. However, the results of our present studies show that the presence of water molecules in a cluster suppresses the dehydration reaction. Although the authors did not state the extent of water impurity, if any, in their system, our finding provides an alternative explanation for the discrepancy between the two studies mentioned above.

For simplicity, only the dehydration mechanism of the protonated acetone dimer is considered here; see Figure 11. The structure of protonated acetone dimer (I) can be written as a combination of the ketone and enol forms, as shown in structure (II) (46). The protonated acetone dimer undergoes a common water elimination reaction through intermediate species (II-V) to yield the protonated mesityl oxide, $\mathrm{C}_{6} \mathrm{H}_{11} \mathrm{O}^{+}(\mathrm{VI})$. When water is present in the system, it can bond to either site A or site B. However, the dehydration reaction of the protonated acetone cluster is quenched if the water molecule is bonded to site A in structure II. See a full discussion of this in Reference (II-272). 
(iii). Photoionized Mass Spectrometry of Ammonia-Acetone Mixed Clusters

Mixed clusters of ammonia and acetone (T) were studied using three different clustering methods (II-285). By using a mixing nozzle in conjunction with a pulsed valve, three methods of mixed cluster formation have been investigated: (i) The coexpansion of a mixture of the two gases through the pulsed nozzle with no gas in the mixing source; (ii) expanding a beam of ammonia through the pulsed nozzle and crossing it with acetone from the mixing source; and (iii) expanding a beam of acetone through the pulsed nozzle and crossing it with ammonia from the mixing source. The three methods produced different dominant cluster structures and the observed unimolecular dissociation varied from method to method. Some very distinct differences were discovered in the mixed cluster spectra of acetone and ammonia. A very strong set of protonated ammonia clusters $\left(\mathrm{NH}_{3}\right)_{\mathrm{n}} \mathrm{H}^{+}$was observed in both methods (i) and (ii). As expected, no pure ammonia clusters were seen in method (iii).

The dominant mixed clusters produced in all three formation methods were $\mathrm{T}_{n} \mathrm{NH}_{4}{ }^{+}$ $(n=1-4)$. Besides a very weak signal of $\mathrm{T}_{n} \mathrm{NH}_{3}{ }^{+}$, the protonated forms with one ammonia were the only mixed clusters detected using formation method (iii). Method (ii) produced a set of protonated, mixed species $\left(\mathrm{T}_{\mathrm{n}}\left(\mathrm{NH}_{3}\right)_{\mathrm{m}} \mathrm{H}^{+}, \mathrm{n} \geq 1, \mathrm{~m}=1-4\right)$, and only the coexpansion produced both protonated and unprotonated species, $\mathrm{T}_{\mathrm{n}}\left(\mathrm{NH}_{3}\right)_{\mathrm{m}}{ }^{+}$and $\mathrm{T}_{\mathrm{n}}\left(\mathrm{NH}_{3}\right)_{\mathrm{m}} \mathrm{H}^{+}$(the protonated forms were much stronger). These mixed clusters showed less variance from method to method but continued to show that discrimination between protonated and unprotonated species is peculiar to the formation method.

The unimolecular dissociation reactions observed in these experiments are shown in Table II. A few of the reactions are worth further discussion. The mixed cluster, $\mathrm{T}_{\mathrm{n}} \mathrm{NH}_{4}{ }^{+}$, lost an acetone molecule during dissociation. This was in contrast to the other mixed species, which lost ammonia. The findings indicate that the ammonia molecule binds to the proton more tightly than the acetone. 
The pure acetone clusters produced in method (iii) showed some interesting dissociations. Our investigation indicated that the fragment $\mathrm{CH}_{3} \mathrm{CO}^{+}$underwent dissociation to produce $\mathrm{CH}_{3}{ }^{+}$and CO. In addition, the protonated acetone monomer produced two different products through unimolecular dissociation. Both $\mathrm{CH}_{3} \mathrm{CO}^{+}$and $\mathrm{CO}^{+}$daughter ions were detected as products from $\mathrm{T}_{1} \mathrm{H}^{+}$.

This investigation provided some very interesting preliminary results in the study of mixed clusters. By using three different sources of clusters, three different types of mass spectra were produced. Through further investigation of these results and continued study of mixed cluster systems, more information regarding the interplay between cluster structure and reactivity is expected to be gained.

\section{c. Establishing the Chemistry of Ions: Compositional and Structural Changes Due to Solvation}

Studies of ion solvation, structure and stability are also under taken by using a reflectron time-of-flight mass spectrometer. In small hydrogen-bonded cluster ions it has been known that the stability is achieved by the symmetric positioning of the molecules around a central proton or protonated species, for example, $\left(\mathrm{CH}_{3} \mathrm{COCH}_{3}\right)_{2} \mathrm{H}^{+}(47),\left(\mathrm{CH}_{3} \mathrm{OCH}_{3}\right)_{3} \mathrm{H}_{3} \mathrm{O}^{+}(48)$, and $\left(\mathrm{NH}_{3}\right)_{4} \mathrm{NH}_{4}^{+}$ (19). Detailed studies of the solvation around $\mathrm{NH}_{4}{ }^{+}$in mixed clusters containing ammonia have been carried out in our laboratory. Depending on the proton affinity (PA) of molecule $X_{v}$ the mixed cluster ions $\left(\mathrm{NH}_{3}\right)_{n}(\mathrm{X})_{\mathrm{m}} \mathrm{H}^{+}$are divided into two categories: (i) PA of molecule $\mathrm{X}$ is less than that of ammonia, and (ii) PA of molecule $\mathrm{X}$ is larger than that of ammonia.

\section{(i) $\mathrm{X}=\mathrm{CH}_{3} \mathrm{COCH}_{3}, \mathrm{CH}_{3} \mathrm{CN}, \mathrm{CH}_{3} \mathrm{CHO}$}

The proton affinity of ammonia is $204.0 \mathrm{cal} / \mathrm{mol}$ and those of $\mathrm{CH}_{3} \mathrm{COCH}_{3}, \mathrm{CH}_{3} \mathrm{CN}$, and $\mathrm{CH}_{3} \mathrm{CHO}$ are $196.7,188.4$, and $186.6 \mathrm{cal} / \mathrm{mol}$, respectively (50). In all three mixed cluster ion 
systems, the ion intensity distributions show that a maximum at $n+m=5$ (II-285). The complete metastable decomposition studies (II-287) of the mixed cluster ions can be summarized as follows:

$$
\begin{aligned}
& \left(\mathrm{NH}_{3}\right)_{\mathrm{n}}(\mathrm{X})_{\mathrm{m}} \mathrm{H}^{+} \rightarrow\left(\mathrm{NH}_{3}\right)_{n}(\mathrm{X})_{\mathrm{m}-1} \mathrm{H}^{+}+\mathrm{X}, \quad \text { for } \mathrm{n}=1 \\
& \left(\mathrm{NH}_{3}\right)_{\mathrm{n}}(\mathrm{X})_{\mathrm{m}} \mathrm{H}^{+} \rightarrow\left(\mathrm{NH}_{3}\right)_{\mathrm{n}-1}(\mathrm{X})_{\mathrm{m}} \mathrm{H}^{+}+\mathrm{NH}_{3} \text {, for } \mathrm{n} \geq 2 .
\end{aligned}
$$

The results clearly indicate that $\mathrm{NH}_{4}{ }^{+}$is the core ion with four available hydrogen-bonding sites to complete the first solvation shell. The four ligands can be in any combination of ammonia and moleculle $X$. The loss of ammonia molecule during metastable decomposition for $n \geq 2$ indicates that $\mathrm{X}$ is more strongly bonded to the $\mathrm{NH}_{4}^{+}$than another $\mathrm{NH}_{3}$. This is not surprising because all molecules listed here have higher dipole moments and polarizabilities than those of ammonia, which leads to a greater ion-dipole and ion-induced dipole interaction.

\section{(ii) $\mathrm{X}=\mathrm{C}_{5} \mathrm{H}_{5} \mathrm{~N}$ and $\left(\mathrm{CH}_{3}\right)_{3} \mathrm{~N}$}

The proton affinities (2O) of pyridine $\left(\mathrm{C}_{5} \mathrm{H}_{5} \mathrm{~N}\right)$ and trimethylamine (TMA, $\left.\left(\mathrm{CH}_{3}\right)_{3} \mathrm{~N}\right)$ are 220.8 and $225.1 \mathrm{cal} / \mathrm{mol}$ which are larger than that of ammonia. The metastable decomposition studies of $\mathrm{NH}_{3}\left(\mathrm{C}_{5} \mathrm{H}_{5} \mathrm{~N}\right)_{\mathrm{m}} \mathrm{H}^{+}(\mathrm{m}=1-5)$ show the following results:

$$
\begin{aligned}
& \mathrm{NH}_{3}\left(\mathrm{C}_{5} \mathrm{H}_{5} \mathrm{~N}\right)_{\mathrm{Im}} \mathrm{H}^{+} \rightarrow\left(\mathrm{C}_{5} \mathrm{H}_{5} \mathrm{~N}\right)_{\mathrm{m}} \mathrm{H}^{+}+\mathrm{NH}_{3} \text {, for } \mathrm{m}<4 \\
& \mathrm{NH}_{3}\left(\mathrm{C}_{5} \mathrm{H}_{5} \mathrm{~N}\right)_{\mathrm{m}} \mathrm{H}^{+} \rightarrow \mathrm{NH}_{3}\left(\mathrm{C}_{5} \mathrm{H}_{5} \mathrm{~N}\right)_{\mathrm{m} \cdot 1} \mathrm{H}^{+}+\mathrm{C}_{5} \mathrm{H}_{5} \mathrm{~N} \text {, for } \mathrm{m} \geq 4
\end{aligned}
$$

The higher proton affinity of pyridine leads to a stronger bonding to the proton and terds to lose the ammonia molecule in the metastable dissociation in the case of $m<4$. The loss of pyridine in the case oll $\mathrm{m} \geq 4$ can be accounted for the fact that a central $\mathrm{NH}_{4}^{+}$core ion is formed to provide four 
hydrogen bonding sites for ligands. This finding is consistent with the previous proposed stable structure for the cluster ion $\left(\mathrm{NH}_{3}\right)_{n}\left(\mathrm{X}_{\mathrm{m}} \mathrm{H}^{+}\right.$.

In the studies of mixed ammonia-trimethylamine, the ion intensity distributions of $\left(\mathrm{NH}_{3}\right)_{\mathrm{n}}(\mathrm{TMA})_{\mathrm{m}} \mathrm{H}^{+}(\mathrm{II}-296)$ display local maxima at $(\mathrm{n}, \mathrm{m})=(1,4),(2,3),(2,6),(3,2)$, and $(3,8)$. The fact that the maximum ion intensity occurs at $(n, m)=(1,4),(2,3)$, and $(3,2)$ indicates that a solvation shell is formed around $\mathrm{NH}_{4}{ }^{+}$ion with four ligands of any combination of ammonia and TMA molecules. In the case of the maximum ion intensity occurring at $(n, m)=(2,6)$ and $(3,8)$, the experimental results suggest that another solvation shell containing core ions $\mathrm{H}_{3} \mathrm{~N}-\mathrm{H}-\mathrm{NH}_{3}{ }^{+}(6$ available hydrogen bonding sites) and $\mathrm{H}_{3} \mathrm{~N}-\mathrm{H}\left(\mathrm{NH}_{2}\right) \mathrm{H}-\mathrm{NH}_{3}{ }^{+}$( 8 available hydrogen bonding sites). The observed metastable unimolecular decomposition processes are:

$$
\begin{aligned}
& \mathrm{NH}_{3}(\mathrm{TMA})_{\mathrm{m}} \mathrm{H}^{+} \ldots>(\mathrm{TMA})_{\mathrm{m}} \mathrm{H}^{+}+\mathrm{NH}_{3}, \quad \mathrm{~m}<4 \\
& \mathrm{NH}_{3}(\mathrm{TMA})_{\mathrm{m}} \mathrm{H}^{+} \ldots>\mathrm{NH}_{3}(\mathrm{TMA})_{\mathrm{m}-1} \mathrm{H}^{+}+\mathrm{TMA}, \quad \mathrm{m} \geq 4 \\
& \left(\mathrm{NH}_{3}\right)_{2}(\mathrm{TMA})_{\mathrm{m}} \mathrm{H}^{+} \ldots>\mathrm{NH}_{3}(\mathrm{TMA})_{\mathrm{m}} \mathrm{H}^{+}+\mathrm{NH}_{3}, \quad \mathrm{~m}<6 \\
& \left(\mathrm{NH}_{3}\right)_{2}(\mathrm{TMA})_{\mathrm{m}} \mathrm{H}^{+} \ldots\left(\mathrm{NH}_{3}\right)_{2}(\mathrm{TMA})_{\mathrm{m}-1} \mathrm{H}^{+}+\mathrm{TMA}, \mathrm{m} \geq 6 \\
& \left(\mathrm{NH}_{3}\right)_{3}(\mathrm{TMA})_{\mathrm{m}} \mathrm{H}^{+} \ldots\left(\mathrm{NH}_{3}\right)_{2}(\mathrm{TMA})_{\mathrm{m}} \mathrm{H}^{+}+\mathrm{NH}_{3}, \quad \mathrm{~m}<8 \\
& \left(\mathrm{NH}_{3}\right)_{3}(\mathrm{TMA})_{\mathrm{m}} \mathrm{H}^{+} \ldots\left(\mathrm{NH}_{3}\right)_{3}(\mathrm{TMA})_{\mathrm{m}-1} \mathrm{H}^{+}+\mathrm{TMA}, \mathrm{m} \geq 8
\end{aligned}
$$

The results from the observed decomposition processes also support the above ion solvation shell model for mixed cluster ions containing ammonia.

Strong evidence was obtained for ring-like structure in other studies conducted on a series of mixed neutral clusters $(A)_{n} \cdot(M)_{m}$ (A is both the proton donor and acceptor such as ammonia and water, $M$ is only a proton acceptor such as acetone, pyridine, and trimethylamine). The observed mixed cluster ions display a maximum intensity at $m=2(n+1)$ when $n \leq 5$ for $\left(\mathrm{NH}_{3}\right)_{n} \cdot(\mathrm{M})_{m} \mathrm{H}^{+}$, 
$m=n+2$ when $n \leq 4$ for $\left(\mathrm{H}_{2} \mathrm{O}\right)_{n} \bullet(M)_{m} \mathrm{H}^{+}$at various experimental conditions (laser powers, expansion conditions, and mixing ratios) indicating that the cluster ions $w$ us these combinations have the stable closed shell structures as discussed above. However, the pattern was found to break down when $n>5$ for ammonia system and $n>4$ for water system. The most intense peaks are reached with one molecule less than the expected pattern is required, i.e. $m=2(n+1)-1$ when $n=6$ for $\left(\mathrm{NH}_{3}\right)_{n} \cdot(\mathrm{M})_{m} \mathrm{H}^{+}$and $\mathrm{m}=(\mathrm{n}+2)-1$ when $\mathrm{n}=5$ for $\left(\mathrm{H}_{2} \mathrm{O}\right)_{n^{\circ}} \cdot(\mathrm{M})_{m} \mathrm{H}^{+}$. This can be explained based on the formation of the hydrogen-bonded ring structures (e.g. $\left(\mathrm{H}_{2} \mathrm{O}\right)_{5}(\mathrm{M})_{6} \mathrm{H}^{+}$drawn below) which are known to exist in the condensed phase.

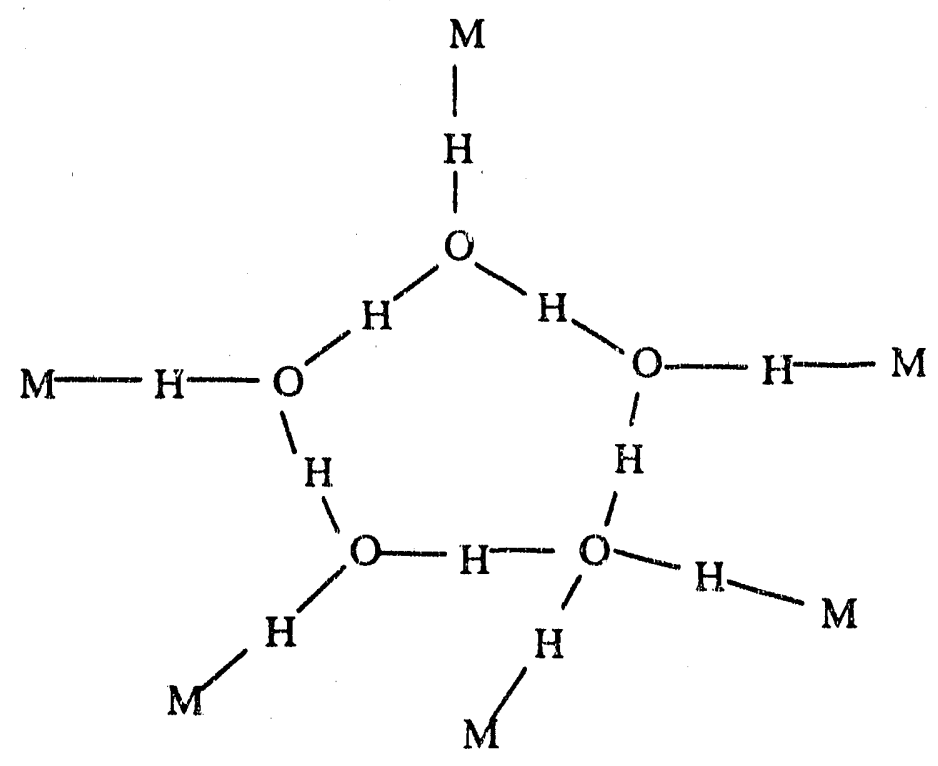

Structure of $\left(\mathrm{H}_{2} \mathrm{O}\right)_{5}(\mathrm{M})_{6} \mathrm{H}^{+}$

Additional studies of metastable and collision induced dissociations of these mixed cluster systems show that the loss channel is well correlated to their structures.

\section{d. The Influence of Hydration on the Behavior of Phosphate Ions}

Interest in the monomeric metaphosphate anion $\mathrm{PO}_{3}{ }^{-}$stems from its proposed intermediary role in phosphorylation and the hydrolysis of phosphate esters (51) and generally from the importance of phosphates to the chemistry of biological systems (52). Interest in the combustion of phosphorus and phosphorus compounds as impurities in coal-fired magnetohydrodynamic 
generators has also motivated study of the $\mathrm{PO}_{3}{ }^{\cdot}$ anion (53-55). The metaphosphate anion has been shown to be relatively stable and unreactive in the gas phase $(56,57)$. However, identification of the species in aqueous solution has been elusive and there is considerable debate over whether $\mathrm{PO}_{3}{ }^{-}$ can exist as a free entity in water (58).

Investigation of the properties of clusters is a convenient method to bridge the states of matter (1). Therefore, in order to attempt to understand the apparent discrepancy in the behavior of $\mathrm{PO}_{3}{ }^{-}$in the gas phase versus the aqueous phase, we have examined the gas phase hydration of the ion by high pressure mass spectrometry, the changes in enthalpy $\Delta H_{n, n+1}^{\circ}$, entropy $\Delta S_{n, n+1}^{\circ}$, and free energy $\Delta G_{n, n+1}^{\circ}$ for the stepwise $(n, n+1)$ hydration gas phase reactions, nominally expressed as

$$
\mathrm{PO}_{3}^{-}\left(\mathrm{H}_{2} \mathrm{O}\right)_{\mathrm{n}}+\mathrm{H}_{2} \mathrm{O} \rightleftharpoons \mathrm{PO}_{3}^{-}\left(\mathrm{H}_{2} \mathrm{O}\right)_{\mathrm{n}+1}
$$

Note that $\mathrm{PO}_{3} \cdot{ }^{-} \mathrm{H}_{2} \mathrm{O}$ is mass spectrometrically indistinguishable from $(\mathrm{HO})_{2} \mathrm{PO}_{2}{ }^{-}$and hydration may lead to the orthophosphate anion. Deuteration is required to displace the hydrated $\mathrm{PO}_{3}{ }^{-}$mass from interfering ion peaks. The thermodynamic quantities for the first association step of $\mathrm{H}_{2} \mathrm{O}$ onto $\mathrm{PO}_{3}{ }^{-}$were determined and are in close agreement with the values for the $(0,1)$ reaction of $\mathrm{D}_{2} \mathrm{O}$ onto $\mathrm{PO}_{3}{ }^{-}$as expected. The data are given in Reference (II-274).

Quantum mechanical caiculations suggest that the gas phase reaction of $\mathrm{PO}_{3}{ }^{-}$with water to give the dihydrogen orthophosphate anion $(\mathrm{HO})_{2} \mathrm{PO}_{2}{ }^{-}$is very exothermic. The present experimental result is considerably less exothermic at about $54 \mathrm{~kJ} / \mathrm{mol}$. In fact, the experimental result is consistent, when compared to gas-phase hydration of $\mathrm{NO}_{3}{ }^{-}$, with simple adduct formation, i.e., association leading to the product $\mathrm{PO}_{3} \cdot \mathrm{H}_{2} \mathrm{O}$. The small decrease in exothermicity for the $(1,2)$ hydration step is also consistent with a simple clustering reaction. However, the common trend of decreasing $-\Delta \mathrm{H}_{n, n+1}^{o}$ and $-\Delta \mathrm{G}_{n, n+1}^{\circ}$ with increasing $n$ is violated by the $(2,3)$ step. The entropy change for this reaction is also notably different from the others. 
Since the many applied tests indicate that equilibrium is attained in the study, the measured result for the $(2,3)$ reaction suggests strongly that this reaction is not the simple clustering of another water $\left(\mathrm{D}_{2} \mathrm{O}\right)$ molecule onto $\mathrm{PO}_{3}^{-}$. In comparison to the initial hydration reactions, the $(2,3)$ step is much more exothermic and exoergic than expected. A plausible exp!anation is that the $\mathrm{PO}_{3}$ hydrate isomerizes to $(\mathrm{DO})_{2} \mathrm{PO}_{2}^{-}$in the presence of three $\mathrm{D}_{2} \mathrm{O}$ molecules.

$$
\mathrm{PO}_{3}^{-}\left(\mathrm{D}_{2} \mathrm{O}\right)_{2}+\mathrm{D}_{2} \mathrm{O} \rightarrow(\mathrm{DO})_{2} \mathrm{PO}_{2}-\left(\mathrm{D}_{2} \mathrm{O}\right)_{2}
$$

The uniquely large entropy change for the $(2,3)$ step is also consistent with Reaction (14) as opposed to a simple clustering reaction.

We may also consider other thermochemical cons/raints to evaluate the plausibility of this interpretation. For $\Delta \mathrm{H}_{\mathrm{f}}{ }^{\circ}\left(\mathrm{PO}_{3}{ }^{\circ}\right)$, Unkel and Freedinan (54) report a value of about $-800 \mathrm{~kJ} / \mathrm{mol}$, whereas Rudnyi and coworkers (53) report values from about -940 to $-990 \mathrm{~kJ} / \mathrm{mol}$. The value from Unkel and Freedman leads to $\Delta \mathrm{H}^{\mathrm{o}}{ }_{\text {acid }}\left[\mathrm{H}_{3} \mathrm{PO}_{4}\right]=1630 \mathrm{~kJ} / \mathrm{mol}$ which is about the same as that for water (35) and is therefore not a reasonable result. The determinations by Rudnyi give $\Delta \mathrm{H}^{\mathrm{o}}{ }_{\text {acid }}\left[\mathrm{H}_{3} \mathrm{PO}_{4}\right]$ of about $1470 \mathrm{~kJ} / \mathrm{mol}$ which is far more reasonable. Our interpretation is therefore consistent with the thermodynamic data of Rudnyi and coworkers. The $(3,4)$ reaction behaves more normally, both kinetically and thermodynamically. The thermodynamic quantities are not unreasonable for a third hydration step of $(\mathrm{DO})_{2} \mathrm{PO}_{2}$ :

The thermodynamic results of this study support the conclusion of Henchman et al. (57) concerning the unreactive nature of $\mathrm{PO}_{3}{ }^{-}$in the gas phase. Our results suggest that the reaction of $\mathrm{PO}_{3}{ }^{-}$with water in the gas phase produces the simple adduct $\mathrm{PO}_{3} \cdot \mathrm{H}_{2} \mathrm{O}$. However, hydration of $\mathrm{PO}_{3}{ }^{-}$by three water molecules leads to a chemical transformation, presumably to the dihydrogen orthophosphate anion. 


\section{e. The Interacticn of Crown Ethers with Ions}

The sodium-potassium cycle in biological systems involves the formation of an ion concentration gradient across cell membranes (59). Generally, the concentration of free potassium inside a cell is much higher than that cutside and vice versa for sodium. In order for this to happen, an ion-specific transport system must be set up eith $x$ by means of channels through the membrane (passive transport) or by free mislecules which bind to an ion and then carry it through the membrane (active transport). Very little is known about the immediate environment of the alkali ions in solution because of the lack of suitable spectral and magnetic properties (60).

Two molecules which are known to be able to carry out active transport in biological systems are valinomycin and nonactin (60). A much simpler molecule which has been shown to have complexing vroperties similar to the larger molecules is dibenzo-18-crown-6-ether (61). Gas phase studies of $\mathrm{Na}^{+}$and $\mathrm{K}^{+}$complexed with this and other large organic molecules which mimic those found in biological systems are userul for two reasons. Not only do they lead to information on the complexing properties of the iarge molecules but also, when compared with solution data, can aid in understanding the effect of the solvent on the ion complex.

One molezule which has been found to be amenable to study is a very simple polyether, 1,2-dimethoxyethane (DME) which exhibits interesting bidentate behavior. Studies with even this relatively simple molecule can give some insight into the binding of the more complex molecule: The following reactions with $n=0$ to 2 were studied earlier and we are now beginning to assess their implications.

$$
\mathrm{Na}^{+}(\mathrm{DME})_{\mathrm{n}}+\mathrm{DME} \stackrel{\mathrm{M}}{\rightleftarrows} \mathrm{Na}^{+}(\mathrm{DME})_{\mathrm{n}+1}
$$

where $M$ is the third-body $\left(N_{2}\right)$ that serves to stabilize the product and ensure equilibrium. 
Thermodynamic properties were determined earlier for the attachment of one, two and three molecules of the simple polyether 1,2-dimethoxyethane to $\mathrm{Na}^{+}$. The values obtained are: $-\Delta \mathrm{H}_{\mathrm{n}, \mathrm{n}+1}$ $=47.2,35.1$ and $23.2 \mathrm{kcal} / \mathrm{mole}$, and $-\Delta S_{n, n+1}=34.6,40.5$, and 42.2 e.u., for $n=1-3$, respectively. Both the enthalpy and entropy values show that the attachment involves interesting bidentate behavior. The findings are compared to recent theoretical computations, indicating that there may be a need to re-evaluate the potential employed. The measurements also have implications in interpreting the binding of alkali metal ions to crown ethers, and, along with other data in the literature, allow consideration of the formation of ion concentration gradients across all membranes involved in the sodium-potassium cycle in biological systems.

There is very little indication that either $\mathrm{Na}^{+}$of $\mathrm{K}^{+}$has an enhanced ability to bind to DME because of a different fit into the structure. Although the ratio $\Delta \mathrm{H}_{0,1}^{\circ}(\mathrm{DME}) / \Delta \mathrm{H}^{\circ}{ }_{0,1}\left(\left(\mathrm{CH}_{3}\right)_{2} \mathrm{O}\right)$ is smaller for $\mathrm{K}^{+}$than $\mathrm{Na}^{+}$, this can be attributed to experimental error in $\Delta \mathrm{H}_{0,1}^{\circ}(\mathrm{DME})$ for $\mathrm{K}^{+}(62)$. Apparently the low energy barrier to structural changes in DME allows it to easily accommodate either ion.

The cyclic polyethers are considerably different in that there is much more steric hindrance involved in the relative movement of the oxygen atoms. Although these molecules are very flexible, the size of the "hole" which they are ultimately able to form in surrounding an ion is limited both by the oxygen-oxygen repulsions and ring strain. Therefore the $\mathrm{M}^{+}-\mathrm{O} d$ cance in a $\mathrm{Na}^{+}$-ether complex is about the same as in a $\mathrm{K}^{+}$. ather complex. Evidence for this is presented for dibenzo-18-crown- 6 ether by Tsatsas et al. (63). The fit is better for the $\mathrm{K}^{+}$complex, i.e., the $\mathrm{M}^{+}-\mathrm{O}$ distance is closer to that expected for an electrostatic interaction with a monodentate species such as $\mathrm{H}_{2} \mathrm{O}$. This is frequently given as an explanation for the better complexing ability of $\mathrm{K}^{+}$to the cyclic polyether. The optimum $\mathrm{K}^{+}-\mathrm{O}$ distance in $\mathrm{K}^{+}\left(\mathrm{H}_{2} \mathrm{O}\right)_{6}$ was calculated by Kistenmacher, Popkie, and Clementi (64) to be $2.79 \AA$. This is very close to the distances found in the $\mathrm{K}^{+}$-valinomycin (65), -nonactin (66), and -dibenzo-18-crown-6 ether (63) complexes. On the other 
hand, the $\mathrm{Na}^{+}-\mathrm{O}$ distance calculated for $\mathrm{Na}^{+}\left(\mathrm{H}_{2} \mathrm{O}\right)_{6}$ was found to be $2.35 \AA$ (assuming a symmetric configuration). Although this suggests that the hole's size within these large molecules is not optimum for $\mathrm{Na}^{+}$, one cannot necessarily conclude that the stability of the $\mathrm{K}^{+}$complex is greater than that of the $\mathrm{Na}^{+}$complex. The $\mathrm{Na}^{+}-\mathrm{O}$ distance would not be optimum in the cyclic ether complexes, but the $\mathrm{Na}^{+}-\mathrm{O}$ repulsion energy is still smaller than the $\mathrm{K}^{+}-\mathrm{O}$ repulsion if one takes the radial dependence of the repulsion to be the same as that of $\mathrm{M}^{+}-\mathrm{O}$ repulsion in $\mathrm{M}^{+}\left(\mathrm{H}_{2} \mathrm{O}\right)_{n}$. Since the attractive potential is similar for $\mathrm{K}^{+}$and $\mathrm{Na}^{+}$at a given ion-ligand separation, the lower repulsion for the $\mathrm{Na}^{+}$means that $\mathrm{Na}^{+}$-complexes will likely be slightly more stable.

A reasonable explanation for the better complexing of $\mathrm{K}^{+}$with the cyclic polyethers in aqueous solution can be given by considering the whole system of solvent and solutes. In order to extract an ion from the aqueous phase into the phase which contains the polyether it must be more stable in the latter (63). Previous studies have shown that all the water must be stripped from the ion before it can complex with the cyclic polyether (60). Therefore, one need only compare the binding energy of the ion to a solvent shell of $\mathrm{H}_{2} \mathrm{O}$ molecules with that to the ether in order to determine in which phase it will be more stable. Dibenzo-18-crown-6 ether is the molecule we use for the comparison and it is assumed that six molecules of $\mathrm{H}_{2} \mathrm{O}$ make up a solvent shell for both $\mathrm{K}^{+}$ and $\mathrm{Na}^{+}$. Reaction (16) is endothermic for $\mathrm{Na}^{+}$and slightly exothermic for $\mathrm{K}^{+}$.

$$
\left.\mathrm{M}^{+}\left(\mathrm{H}_{2} \mathrm{O}\right)_{6}+\text { crown ether } \rightleftharpoons \mathrm{M}^{+} \text {(crown ether }\right)+6 \mathrm{H}_{2} \mathrm{O}
$$

The conclusion is that the free energy change for the above reaction is more favorable for $\mathrm{K}^{+}$than $\mathrm{Na}^{+}$because the restrictions of hole size in the polyether do not allow an optimum configuration for $\mathrm{Na}^{+}$. Although the stabilities of $\mathrm{K}^{+}$(crown ether) and $\mathrm{Na}^{+}$(crown ether) are probably similar in the gas phase, $\mathrm{Na}^{+}$is more strongly bound than $\mathrm{K}^{+}$to the water molecules. Therefore, complexation with the crown ether is less favorable in aqueous solution. 


\section{f. Studies of Photodissociation and Photoinitiated Reactions}

\section{(i). Development of a New Technique}

Recently, we conceived of a new technique (II-290) which would be very amenable to investigating electron transfer reactions in clusters which are planned for the new program. As a prelude to such studies, we tested its validity and usefulness in conducting a study of the photodissociation dynamics of chlorobenzene. A molecular beam is generated by sending pulses of a gas mixture through a $0.7 \mathrm{~mm}$ nozzle into a near vacuum; this "supersonic" expansion cools the gas to near zero Keivin. The nozzle is pointed toward a $1 \mathrm{~mm}$ skimmer allowing a $1 \mathrm{~mm}$ column of gas to pass into another vacuum chamber and enter a set of asceleration grids. One or more beams from a pair of pumped dye lasers enter the second chamber through a window and intersect the molecular beam within the acceleration grids, selectively ionizing molecules that can absorb at the selected frequencies. The ions are then accelerated by the electric field applied to the acceleration grids to the far end of the chamber, where they encounter another set of grids reflecting them back to the detector mounted adjacent to the acceleration region.

In the ordinary mode of operation, assuming the ions do not dissociate, all singly charged ions in the drift region (after acceleration) have the same kinetic energy; the potential at the ionization point (birth potential) times the charge. If, however, a molecule becomes unstable upon ionization and dissociates in the drift region, it loses a fraction of its mass while retaining (approximately) its original velocity, thus losing that fraction of its kinetic energy. The amount of energy lost is independent of where in the drift region the dissociation took place. If, on the other hand, the dissociation takes place within the acceleration region, the ion loses the same fraction of its kinetic energy at that point, while any further energy obtained after the dissociation is retained. Thus, for a dissociating ion with a known initial and final mass, its kinetic energy can be used to calculate where, and subsequently when, the dissociation took place. 
In the new method developed in our laboratory for measuring dissociation rates, the potential on the reflection grid is varied and a complete mass spectrum recorded at each potential. At any potential below the birth potential, any non-dissociative ions pass entirely through the reflecting grids and are not detected; also, some of the dissociated ions (those which dissociated earlier and retained most of the acceleration energy) have enough kinetic energy to pass through. The logarithm of the area of the mass peak is then plotted against the time of dissociation calculated for an ion that would just barely be reflected by the grid potential, and the slope is $-\mathrm{K}$, where $\mathrm{K}$ is the dissociation rate constant. Congestion of the mass spectra, a problem in all other methods used, usually has no effect in our cas:; because all non-dissociating ions are reflected by the low reflecting-field strength. In a paper just published (II-290), we report results obtained on the chlorobenzene ion, which agree reasonably well with the results of Durant et al. (67) who used a related but inferior method.

A related method, also developed here, measures dissociation rates of ions in the drift region by progressively lowering the reflection potential until the ions dissociating in the drift region drop out of the spectrum. This happens all at once, since "daughters" formed after acceleration all carry the same kinetic energy, and by using the ratio of this drop to original area of the peak at a potential above the birth potential, and calculating the time spent between acceleration and reflection, a rate constant can be obtained. Also, the voltage at which these daughters drop out gives an unambiguous measure of their final mass, and multiple pathways are easily seen as multiple steps, allowing branching ratios to be easily obtained.

\section{(ii). Photoinitiated reactions}

It has been known for some years (7) that, following ionization, reactions that have direct analogy with those which occurred between similar species in the gas phase can proceed within clusters. Recently, there has been growing interest in reactions which display a dependence on the 
degree of cluster aggregation (36). An especially interesting observation is that reactions can be initiated through processes analogous to Penning ionization, where the excited species which is responsible is found to be the original neutral cluster (68).

During the course of recent studies of successive spectroscopic shifts in the region of the $\mathrm{O}_{0}{ }^{\circ}$ band of the $\mathrm{S}_{1}-\mathrm{S}_{0}$ transition of phenylacetylene (PA) complexed with ammonia, we found the occurrence of an internal ion molecule reaction which leads to the formation of specific sizes of protonated ammonia clusters (II-227,256) The photon energies and laser fluences are varied such that direct ionization is not possible and hence these cluster ions can only occur because of some charge transfer reaction taking place within the clusters. The intracluster reactions were investigated using the pulsed laser time-of-flight mass spectrometer (TOFMS) system. Resonance enhanced ionization near the $\mathrm{O}_{0}{ }^{\circ}$ origin of the $\mathrm{S}_{1}-\mathrm{S}_{0}$ transition in PA is employed to initiate the reactions and conventional TOFMS is used to analyze the resulting cluster ion products.

As in the case of the surface-cluster studies, the clusters were generated by two different methods. In one technique, clusters of $\mathrm{PA}\left(\mathrm{NH}_{3}\right)_{\mathrm{n}}$ are made by coexpanding a mixture of $\mathrm{PA}, \mathrm{NH}_{3}$ and argon $(<1 \%, 2 \%, 98 \%)$ through a pulsed valve equipped with a $0.075 \mathrm{~cm}$ diameter orifice. Conditions were chosen to maximize the size and cooling of the clusters while at the same time minimizing the concentration of clusters containing two or more PA molecules. In a second series of experiments, the PA chromophore is attached to preformed clusters of ammonia. These clusters are created by crossing an effusive beam of PA and helium (ratio=1.4) with an ammonia cluster beam exiting from the pulsed nozzle. Ammonia cluster beam conditions are typically 4400 torr of ammonia in argon (50\%) at room temperature.

A sequence of internal cluster ion reactions was observed to occur in clusters of phenylacetylene and ammonia molecules, $\mathrm{PA}\left(\mathrm{NH}_{3}\right)_{\mathrm{n}}$. The sequence consists of a CT reaction between a resonantly ionized $\mathrm{PA}^{+}$ion and the attached ammonia molecules which is then followed by an intraclusters ion-molecule reaction taking place among the ammonia molecules in the cluster. 
The appearance of $\mathrm{H}^{+}\left(\mathrm{NH}_{3}\right)_{n}$ cluster ions, where $\mathrm{n}=2-5$, and the similarity of these spectra with the spectra of $\mathrm{PA}\left(\mathrm{NH}_{3}\right)_{n}$, where $n \geq 5$, p:ovides an upper limit for the IP of $\left(\mathrm{NH}_{3}\right)_{n}$ clusters, where $n \geq 5$, equal to the IP of PA which is $8.8 \mathrm{eV}$. See Figure 12. This cluster size dependent reaction is only possible due to the collective effects of clustered ammonia molecules.

\section{(iii). Investigating Mechanisms}

Study of the photodissociation of the rare-gas cluster ions has been the subject of several recent experimental and theoretical investigations. Such studies have been stimulated by the important role these ions play in rare gas excimer lasers, as well as by the fact that their comparative simplicity allows comparison between experiments and theories. Such comparison is crucial in understanding a wide range of phenomena including transitions from the gas to aggregated and ultimately the condensed phase (1), elucidation of the origin of magic numbers which often arise in studies of cluster distributions in molecular beams, and investigations of energy transfer and metastability (II-248). The findings in our laboratory have also provided a base-line test for evaluating our techniques as a prelude to a study of energy transfer in other systems more relevant to the DOE program and discussed in the proposed studies section.

There have been numerous experimental and theoretical studies of $\mathrm{Ar}_{3}{ }^{+}$cation ion. Interest in $\mathrm{Ar}_{3}{ }^{+}$, in particular, has been prompted by observations (75) that large cluster ions of argon readily photodissociate, and there are indications that the trimer may be the chromophore. From a practical viewpoint, $\mathrm{Ar}_{3}{ }^{+}$is of importance in power loss in XeF excimer lasers. Models $(76,77)$ have suggested that $\mathrm{Ar}_{3}{ }^{+}$is likely to be formed in the intense, high pressure discharges which occur in $\mathrm{XeF}$ lasers and that $\mathrm{Ar}_{3}{ }^{+}$may be the transient absorber in these laser plasmas. Absorption by $\mathrm{Ar}_{3}{ }^{+}$near $500 \mathrm{~nm}$, with a cross section $>10^{-17} \mathrm{~cm}^{2}$, would significartly reduce the output energy of the A $-\mathrm{C}$ transition of a XeF excimer laser. 
The apparatus, including the supersonic beam-electron beam ion source, has been described in detail elsewhere (78). Briefly, it consists of the source chamber, a system of ion optics that provides a well-defined geometry and energy for the beam, a Wien velocity filter for initial mass selection, a tunable dye laser pumped by an argon ion laser, and a quadrupole mass spectrometer.

The photodissociation spectrum of a mass-selected bean of $\mathrm{Ar}_{3}{ }^{+}$(corresponding to approximately one picoampere focused onto a Faraday probe located in the laser interaction region). The relative cross-section is seen to rise with photon energy from $2.00 \mathrm{eV}(620 \mathrm{~nm})$ to $2.38 \mathrm{eV}(520 \mathrm{~nm})$. The absolute cross-section of photodissociation from 540 to $570 \mathrm{~nm}$ wavelength was measured; see Reference (II-275). Power studies at $590 \mathrm{~nm}, 575 \mathrm{~nm}$, and $545 \mathrm{~nm}$ indicate that dissociation is a one-photon process. Photodissociation of $\mathrm{Ar}_{3}{ }^{+}$is found to occur at all wavelengths between $520 \mathrm{~nm}$ and $640 \mathrm{~nm}$. The value of the cross section is found to be about $1.8 \times 10^{-16} \mathrm{~cm}$ at $520 \mathrm{~nm}$.

There are two possible channels which could account for the formation of $\mathrm{Ar}^{+}$from $\mathrm{Ar}_{3}{ }^{+}$. One channel is a concerted loss of both Ar units, while the second involves the sequential loss of Ar. These two channels are indistinguishable on the time scale of our spectroscopic experiments, approximately 20 microseconds from the laser interaction region to the quadrupole detection. However, the two can be distinguished by energy analysis of the photofragments as explained below. Hence, measurements of translational energy release were made in order to further elucidate the mechanisms of energy absorption and dissociation.

In the photodissociation processes, the total energy

$$
E_{a v}=h v-D_{0}+E_{i n t}{ }^{P}=E_{i n t}{ }^{F}+E t_{\imath}
$$

Here, hv is the energy of the absorbed photon and $D_{0}$ is the dissociation energy of the ground state of the parent to the ground state of the fragments, and $\mathrm{E}_{\mathrm{int}}{ }^{\mathrm{P}}$ is the internal energy of the $\mathrm{Ar}_{3}{ }^{+}$ion. The $\mathrm{D}_{\mathrm{o}}$ for $\mathrm{Ar}_{3}{ }^{+}$dissociation to $\mathrm{Ar}_{2}{ }^{+}\left({ }^{2} \Sigma_{\mathrm{u}}\right)$ and $\mathrm{Ar}$ or $\mathrm{Ar}^{+}\left({ }^{2} \mathrm{P}_{3 / 2}\right)$ and 2 Ar were determined experimentally as $0.22 \mathrm{eV}$ and $2.52 \mathrm{eV}$, respectively. The $\mathrm{E}_{\mathrm{int}}{ }^{\mathrm{P}}$ is considered negligible because the 
internal temperature of the ion clusters is very low due to the method of the cluster ion production and the geometric cooling effect in the supersonic expansion beam experiments. How the available energy $\mathrm{E}_{\mathrm{av}}$ becomes partitioned between the center-of-mass frame-translational energy of the photofragment, $E_{\mathrm{l}}$, and the internal energy of the fragment, $\mathrm{E}_{\text {int }}{ }^{\mathrm{F}}$, will totally depend on the photodissuciation mechanism through which the photodissociation of $\mathrm{Ar}_{3}{ }^{+}$occurs.

There are several dissociation mechanisms energetically accessible in $\mathrm{Ar}_{3}{ }^{+}$ photodissociation. These are considered as follows:

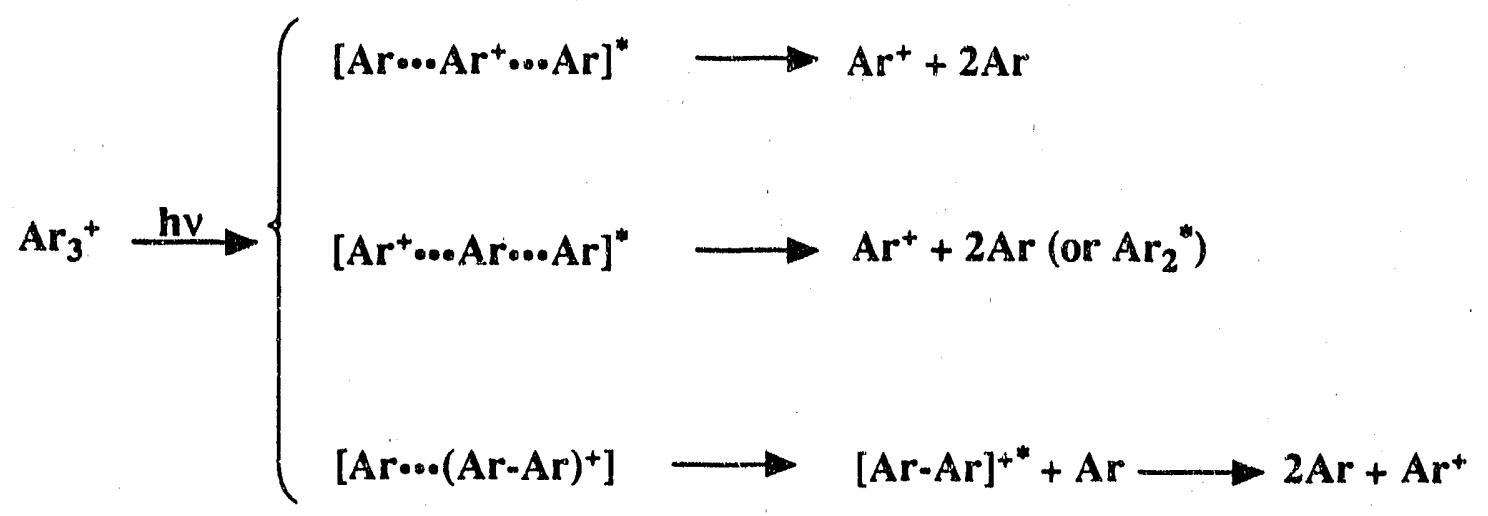

If the lifetimes of the transition states in reactions (18a), (18b), and (18c) are shorter than their rotational periods, they should carry different translational energy which converts from excess electronic excited energy in the photodissociation reaction.

The photofragment translational energy analysis is used to study these mechanisms of photor'issociation of $\mathrm{Ar}_{3}{ }^{+}$. It is found that phoi dissociation involves all three types of mechanisms which result in different amounts of translational energy released from electronic excitation. This translational energy is further confirmed by a study using different photon energies. In the photodissociation of $\mathrm{Ar}_{3}{ }^{+}$, Mechanism (a) and (b), the photodissociation may involve electronic direct dissociation. In Mechanism (c), photodissociation may involve electronic predissociation occurring at crossing electronic energy surfaces. The photodissociation mechanism will depend upon the energy of the photon used in the reaction and the other thermodynamical conditions for the parent preparation. 
Similar photodissociation studies have also been carried out for $\mathrm{Kr}_{\mathrm{n}}{ }^{+}$(II-288). In these studies, the photodissociation of $\mathrm{Kr}_{\mathrm{n}}{ }^{+}(3 \leq \mathrm{n} \leq 11)$ cluster ions is observed for the first time in the $565 \mathrm{~nm}$ to 630 nm wavelength range. $\mathrm{Kr}_{3}{ }^{+}$has a photodissociation cross-section of $(8.1 \pm 0.8) \times 10^{-17} \mathrm{cr}_{3-}{ }^{2}$ at $612 \mathrm{~nm}$, while $\mathrm{Kr}_{4}{ }^{+}$and $\mathrm{Kr}_{5}{ }^{+}$are found to have larger photodissociation cross-sections than $\mathrm{Kr}_{3}{ }^{+}$with a slightly red-shifted spectrum. Only $\mathrm{Kr}^{+}$is detected as a photofragment of $\mathrm{Kr}_{3}{ }^{+}$, while in the $\mathrm{Kr}_{\mathrm{n}}{ }^{+}(4 \leq n \leq 7)$ experiments, both $\mathrm{Kr}_{2}{ }^{+}$and $\mathrm{Kr}^{+}$photofragments are seen. As size $\mathrm{n}$ increases from 7 to $11, \mathrm{Kr}^{+}$ disappears and $\mathrm{Kr}_{3}{ }^{+}$appears. Laser power studies show that all are single photon photodissociation processes. For higher order $\mathrm{Kr}_{\mathrm{n}}{ }^{+}$clusters $(4 \leq n \leq 7)$ the intensity ratio between the two photodissociation products $\mathrm{Kr}_{2}{ }^{+}$and $\mathrm{Kr}^{+}$is dependent on the wavelength of the laser light used in the ph ntodissociation, but independent of the polarization direction of the laser.

Translational energy analysis of the photofragments is used to ir.vestigate the photodissociation mechanisms. In contrast to the photodissociation of $\mathrm{Kr}_{3}{ }^{+}$, where two types of $\mathrm{Kr}^{+}$photofragments with different values of translational energy release are observed, only one type of $\mathrm{Kr}_{2}{ }^{+}$photofragment, with zero kinetic energy release is found in the $\mathrm{Kr}_{4}{ }^{+}$photodissociation. These findings are discussed in terms of the dynamics of photodissociation and possible structures of these cluster ions in Reference (II-288). With the development of the methods using rare gas ions, we are now in a position to pursue photoinduced reactions of relevance to the radiobiology problems discussed in Section IV.

Unimolecular decay of cluster ions has become a subject of extensive interest with metastability (with lifetimes up to several hundred microseconds) being observed in a wide variety of chemically different systems. The interest in such studies stems from the role of unimolecular decay in the origin of magic numbers (79) and in the testing of various theories and mechanisms for such processes $(30,31,80-82)$.

The role of rotational tunneling in effecting the very long metastable lifetime of $\mathrm{Ar}_{3}{ }^{+}$was also examined in a previous study (11-248). Theoretical considerations presented indicated that there exists 
a few percent likelihood of observing tunneling lifetimes from $10^{-10}$ to 1 second. Thus, tunneling through rotational barriers may contribute to the long lifetimes observed in a wide variety of clusters. In an attempt to determine the likelihood that tunneling through rotational barriers is a general mechanism in clusters, the probability of tunneling in larger argon cluster ions was investigated (II-269).

Calculations are performed using several different rotational distributions; the results are divided into order of magnitude transmission coefficient intervals. The results indicate that their exists a probability of at least several percent having tunneling transmission coefficients ranging over ten orders of magnitude. Similar distributions are obtained for all argon cluster ions investigation, $\mathrm{Ar}_{n=2-11}^{+}$. Tunneling can and does occur in all clusters investigated. From $\mathrm{Ar}_{3}{ }^{+}$to larger clusters, the probabilities are fairly insensitive to size, although the form of the dependence changes with the form of the rotational distribution. This trend is consistent with predictions of size insensitivity (83). 
II. Publications which were Submitted or Appeared in Print During the Grant Period March, 1988 - August 1990. (Those sponsored by DOE are designated by *)

227. "Photophysics of Clusters: Intracluster Reactions and Dynamics of Dissociation Processes," A. W. Castleman, Jr., W. B. Tzeng, S. Wei, and S. Morgan, J. Chem. Soc. Faraday Trans. 86, 2417 (1990).*

229. "Ion-Molecule Reactions Involving $\mathrm{H}_{3} \mathrm{O}^{+}, \mathrm{H}_{2} \mathrm{O}^{+}$, and $\mathrm{OH}^{+}$at Thermal Energy," $\mathrm{R}$. J. Shul, $\mathrm{R}$. Passarella, L. T. Difazio, Jr., R. G. Keesee, and A. W. Castleman, Jr., J. Phys. Chem. 92, 4947 (1988).

241. "Clusters: Ionization, Reactions and Properties," A. W. Castleman, Jr. and R. G. Keesee, in Elemental and Molecular Clusters in Materials Science, (G. Benedik, T. P. Martin, and G. Pocchioni, Eds.) pp. 307-328 (1988).*

244. "The Hydration of Monomeric Metaphosphate," R. G. Keesee and A. W. Castleman, Jr., Proc. 1987 Scientific Conference on Chemical Defense Research, Aberdeen Proving Ground, MD, November 17-20, pp. 1221-1226 (1988).

245. "The Properties of Organic Compounds in Molecular Clusters," R. G. Keesee and A. W. Castleman, Jr., Aerosol Science and Technology, 10, 352 (1989).*

246. "Gas Phase Clusters: Spanning the States of Matter," A. W. Castleman, Jr. and R. G. Keesee, invited review, Science 241, 36 (1988).*

247. "Application of Advanced Laser and Newly Developed Time-of-Flight Mass Spectrometer Techniques in Detecting Specific Molecules Bound to Aerosol Precursors," A. W. Castleman, Jr. and R. G. Keesee, Proc. 1987 Scientific Conference on Chemical Defense Research, Aberdeen Proving Ground, MD, November 17-20, pp. $879-888$ (1988).

248. "The Role of Rotational Tunneling in the Metastable Decay of Rare Gas Cluster Ions," E. Ferguson, C. R. Albertoni, R. Kuhn, Z. Y. Chen, R. G. Keesee, and A. W. Castleman, Jr., J. Chem. Phys. 88, 6335 (1988).

249. "Appearance Potentials of $\mathrm{C}_{\mathrm{n}} \mathrm{H}_{2 \mathrm{n}+2} \mathrm{~N}^{+}$Ions," S. W. Sigsworth, R. G. Keesee, and A. W. Castleman, Jr., J. Am. Chem. Soc., 110, 6682 (1988)."

250. "Multiphoton Ionization of Clusters: Reactions and Spectroscopy," A. W. Castleman, Jr. and R. G. Keesee, in The Structure of Small Molecules and Ions (R. Naaman and Z. Vager, Eds.) Plenum Press, New York, pp. 133-145 (1988).

251. "Photodissociation of Rare Gas Cluster Ions: $\mathrm{Ar}_{3}{ }^{+}$, " C. R. Albertoni, R. Kuhn, H. W. Sarkas and A. W. Castleman, Jr., Proc. International Laser Science Conference (ILS-III), November 1-5, Atlantic City, NJ (1987).

252. "Studies of the Dissociation Products of Methylnitrite and Deuterated Methylnitrite lons at High Mass Resolution," M. P. Irion, A. Selinger, A. W. Castleman, Jr., E. Ferguson, and K. G. Weil, Chem. Phys. Lett. 147, 33 (1988). 
253. "Clusters: Elucidating Gas to Particle Conversion Proresses," A. W. Castleman, Jr., Env. Sci. Tech. 22, 1265 (1988).*

254. "Photoabsorption and Photoionization of Clusters," R. G. Keesee and A. W. Castleman, Jr., in Atomic and Molecular Clusters (E. R. Bernstein, Ed.) Elsevier Science, pp. 507-550 (1990).*

255. "Invesigation of the Stabilities of Neutral and Ionic Lead and Lead-Antimony Clusters Under Single and Multiphoton Ionization Conditions," R. W. Farley, P. J. Ziemann, and A. W. Castleman, Jr., Zeitschrift für Physik D 14, 353 (1989).*

256. "Intracluster Reactions in Phenylacetylene Ammonia Clusters Initiated Through Resonant Enhanced Ionization," J. Breen, W.-B. Tzeng, R. G. Keesce, and A. W. Castleman, Jr., J. Chem. Phys., 90, 19 (1989).*

257. "Spectroscopy of Phenylacetylene Bound to Clusters of Ammonia and the Surface Cluster Analogy," J. J. Breen, K. Kilgore, S. Wei, W.-B. Tzeng, R. G. Keesee, and A. W. Castleman, Jr., J. Chem. Phys., 90, 11 (1989).*

258. "Spectroscopy of Phenylacetylene-Carbon Dioxide Clusters," J. Breen, W.-B. Tzeng, R. G. Keesee and A. W. Castleman, Ir., Chem. Phys. Lett., 150, 231 (1988).

259. "Reactions of Hydrogen Halides with Clusters of Ammonia Molecules," J. Breen, K. Kilgore, S. Wei, W.-B. 7izeng, R. G. Keesee and A. W. Castleman, Jr., J. Phys. Chem. 93, 7703 (1989).*

260. "Rates of Hydride Abstraction from Amines via Reactions with Ground State $\mathrm{Ag}^{+}$and $\mathrm{Cu}^{+}$, S. W. Sigsworth and A. W. Castleman, Jr., J. Am. Chem. Soc., 111, 3566 (1989).*

261. "Reactions of Methanol Clusters Following Multiphoton Ionization," S. Morgan, R. G. Keesee and A. W. Castleman, Jr., J. Am. Chem. Soc., 111, 3841 (1989).*

262. "Dissociation Dynamics of Methanol Clusters Following Multiphoton Ionization," S. Morgan and A. W. Castleman, Jr., J. Phys. Chem., 93, 4544 (1989).

263. "Dissociation of Ammonia Cluster Ions Following Their Formation Via Multiphoton lonization," $\mathrm{K}$. Kilgore, S. Morgan, W. B. Tzeng, and A. W. Castleman, Jr., J. Chem. Phys., submitted.*

264. "Structure of Solvated Cluster Ions," R. G. Keesee and A. W. Castleman, Jr., in Ion and Cluster Spectroscopy and Structure, (J. Maier, Ed.) Elsevier Science Publishers, pp. 275-327 (1989).*

265. "Spectroscopy of the Phenylacetylene-Ammonia Cluster System," J. J. Breen, W. B. Tzeng, R. G. Keesee, and A. W. Castleman, Jr., Proc. 1988 CRDEC Obscuration and Aerosol Scientific Conference, June 21-24, 1988, Aberdeen Proving Ground, MD. *

266. "Atom Clusters," A. W. Castleman, Jr., in 7th Edition, McGraw-Hill Encyclopedia of Science and Technology, McGraw-Hill Publishers, in press.

267. "Observation of Gas Phase Anionic Bismuth Zintl Ions," R. W. Farley and A. W. Castleman, Jr., J. Am. Chem. Soc. 111, 2735 (1989).* 
268. "The Use of Laser Spectroscopy in Studying the Attachment of Molecules to Finely Dispersed Colloidal Media," W. B. Tzeng, J. J. Breen, K. Kilgore, S. Wei, R. G. Keesee and A. W. Castleman, Jr., Proc. 1988 U.S. Army CRDEC Conference, November 14-18, 1988. Aberdeen Proving Ground, MD.*

269. "Consideration of Rotational Tunneling in Rare Gas Cluster Ions," C. R. Albertoni, A. W. Castleman, Jr., and E. E. Ferguson, Chem. Phys. Lett. 157, 159 (1989)."

270. "Thermodynamics for the Clustering of Ammonia Onto $\mathrm{Pb}^{+}$in the Gas-Phase," K. L. Gleim, B. C. Guo, R. G. Keesee, and A. W. Castleman, Jr., J. Phys. Chem. 93, 6805 (1989).*

271. "Thermal Energy Ion-Molecule Association Reactions Involving Sodium Ions," R. Passarella and A. W. Castleman, Jr., J. Phys. Chem. 93, 5840 (1989).

272. "Multiphoton Ionization of Acetone Clusters: Metastable Unimolscular Decomposition of Acetone Cluster Ions and the Influence of Solvation on Intracluster Ion-Molecule Reactions," W. B. Tzeng, S. Wei and A. W. Castleman, Jr., J. Am. Chem. Soc. 111, 6035 (1989); "Erratum," J. Am. Chem. Soc. 111, 8326 (1989).*

273. "Thermochemical Properties of Ion Complexes $\mathrm{Na}^{+}(\mathrm{M})_{\mathrm{n}}$ in the Gas Phase," B. C. Guo, B. J. Conklin and A. W. Castleman, Jr., J. Am. Chem. Soc. 111, 6506 (1989).

274. "The Hydration of Monomeric Metaphosphate Anion in the Gas Phase," R. G. Keesee and A. W. Castleman, Jr., J. Am. Chem. Soc. 111, 9015 (1989).*

275. "Ar ${ }_{3}^{+}$Photodissociation and its Mechanisms," Z. Y. Chen, C. R. Albertoni, M. Hasegawa, R. Kuhn, and A. W. Castleman, Jr., J. Chem. Phys. 91, 4019 (1989).*

276. "Thermal Metal Cluster Anion Reactions: Behavior of Aluminum Clusters with Oxygen," R. E. Leuchtner, A. C. Harms, and A. W. Castleman, Jr., J. Chem. Phys. 91, 2753 (1989).

277. "Large Protonated Water Clusters $\mathrm{H}^{+}\left(\mathrm{H}_{2} \mathrm{O}\right)_{\mathrm{n}}$, $(\mathrm{n}=1-49)$ : The Production and Reactivity of Clathrate-Like Structures Under Thermal Conditions," Xiaolin Yang and A. W. Castleman, Jr., J. Am. Chem. Soc. 111, 6845 (1989).

278. "Particle Formation: Clusters and Nuclej," A. W. Castleman, Jr., Proc. 1989 IFPRI 10th Annual Meeting, Teaneck, New Jersey, June 4-8, 1989.*

279. "Metal Cluster Cation Reactions: Carbon Monoxide Association to $\mathrm{Cu}_{n}^{+}{ }^{+}$Ions," $\mathrm{R}$. E. Leuchtner, A. C. Harms and A. W. Castleman, Jr., J. Chem. Phys. 92, 6527 (1990).

280. "Kinetics and Mechanism Studies of Switching and Association Reactions Involving $\mathrm{Na}^{+}$-Ligand Complexes," Xiaolin Yang and A. W. Castleman, Jr., J. Chem. Phys., in press.

281. "Kinetic Energy Release Measurement of Arnmonia Cluster Ions During Metastable Decomposition and Determination of Ciuster Ion Binding Energy," S. Wei, W. B. Tzeng and A. W. Castleman, Jr., J. Chem. Phys. 92, 332 (1990)。* 
282. "Protonated Acetaldehyde Clusters: Stability, Structure, and Metastable Unimolecular Decomposition," W. B. Tzeng, S. Wei, and A. W. Castleman, Jr., Chem. Phys. Lett. 168, 30 (1990).

283. "The Energy Dependence of the Reaction of $\mathrm{N}_{2}{ }^{+}$with $\mathrm{CS}_{2}$, , R. Passarella, Xiaolin Yang, R. G. Keesee, and A. W. Castleman, Jr., J. Mass Spectrom. Ion Proc. 97, 125 (1990).

284. "Reactions of Intermetallic Clusters," R. W. Farley and A. W. Castleman, Jr., J. Chern. Phys. 92 , 1790 (1990).*

285. "Ammonia-Acetone Mixed Clusters: Internal Ion-Molecule Reactions, Structure and Bonding," W. B. Tzeng, S. Wei, D. W. Neyer, R. G. Keesee and A. W. Castlernan, Jr., J. Am. Chem. Soc. 112, 4097 (1990).*

286. "The Clustering of 1,2 Dimethoxyethane, $\left(\mathrm{CH}_{3} \mathrm{OCH}_{2}\right)_{2}$ to Sodium Ion," K. I. Peterson and A. W. Castl man, Jr., J. Am. Chem. Soc., submitted.*

287. "Influence of Solvation on Dissociation: Metastable Unimolecular Decomposition of Mixed Ammonia-Acetone Cluster Ions," W. B. "Tzeng, S. Wei, and A. W. Castleman, Jr., Chem. Phys. Lett. 166, 343 (1990).

288. "Photodissociation of $\mathrm{Kr}_{\mathrm{n}}{ }^{+}$Clusters," Z. Y. Chen. C. D. Cogley, J. H. Hendricks, B. D. May, and A. W. Castleman, Jr., J. Chem. Phys., in press. *

289. "Ion Dip Spectroscopy of van der Waals Clusters," R. J. Stanley and A. W. Castleman, Jr., J. Chem. Phys. 92, 5770 (1990).*

290. "Unimolecular Dissociation Rate Constants: Chlorobenzene Cations Revisited Using a New Method," R. J. Stanley, M. C. Cook, and A. W. Castleman, Jr., J. Phys. Chem. 94, 3668 (1990).*

291. "A Consideration of the Chemistry of Radon Progeny," A. W. Castleman, Jr., Environ. Sci. Tech., in press.

292. "Investigation of the Reactivity of Lead and Bismuth Positive Ions," S. W. Sigsworth and A. W. Castleman, Jr.," Chem. Phys. Lett., 168, 314 (1990).

293. "The Clustering Reactions of Benzene with Sodium and Lead Ions," B. C. Guo, J. W. Purnell, and A. W. Castleman, Jr., Chem. Phys. Lett, 168, 155 (1990).

294. "Studies of Group III Cation Reactions: Consecutive Association of Methanol to $\mathrm{Al}^{+}, \mathrm{Ga}^{+}$, and $\mathrm{In}^{+}$," R. E. Leuchtner, R. W. Farley, A. C. Harms, H. Funasaka, and A. W. Castleman, Jr., Int. J. Mass Spectrom. Ion Proc., in press.

295. "Observation of Isomeric Cluster Ions: Influence on the Dynamics of Dissociation of the Ammonia-Triethylamine System," S. Wei, W. B. Tzeng and A. W. Castleman, Jr., J. Phys. Chem., in press.* 
296. "The Structure of Protonated Solvation Complexes: Ammonia-Trimethylamine Cluster Ions, and Their Metastable Decompositions," S. Wei, W. B. Tzeng and A. W. Castleman, Jr., J. Phys. Chem., in press.*

297. "Dissociation Dynamics: Measurements of Decay Fractions of Metastable Ammonia Cluster Ions," S. Wei, W. B. Tzeng and A. W. Castleman, Jr., J. Chem. Phys., submitted.*

298. "Gas Phase Reactivity of Metal Alloy Clusters," A. C. Harms, R. E. Leuchtner, S. W. Sigsworth and A. W. Castleman, Jr., J. Am. Chem. Soc. 112, 5672 (1990).

299. "The Association Reactions of $\mathrm{Pb}^{+}$Ion with $\mathrm{CH}_{3} \mathrm{OH}$ and $\mathrm{CH}_{3} \mathrm{NH}_{2}$ in the Gas Phase," B. C. Guo and A. W. Castleman, Jr., Int. J. Mass Spectrom. Ion Proc., in press.

300. "The Thermodynamics of Gas-Phase Mixed Solvent Cluster Ions: Water and Methanol on $\mathrm{K}^{+}$and $\mathrm{Cl}^{-}$and Comparison to Liquid Solutions," D. H. Evans, R. G. Keesee, and A. W. Castleman, Jr., J. Am. Chem. Soc., submitted.

301. "Production and Magic Numbers of Large Hydrated Anion Clusters $X-\left(\mathrm{H}_{2} \mathrm{O}\right)_{\mathrm{N}}=0.59, \mathrm{X}=\mathrm{OH}, \mathrm{O}, \mathrm{O}_{2}$ and $\mathrm{O}_{3}$, Under Thermal Conditions," $\mathrm{X}$. Yang and A. W. Castleman, Jr., J. Phys. Chem., submitted.*

302. "Stabilities and Structures of Gas Phase MgO Clusters," P. J. Ziemann and A. W. Castleman, Jr., J. Chem. Phys., submitted.

303. "Aluminum Cluster Reactions," R. E. Leuchtner, A. C. Harms, and A. W. Castleman, Jr., J. Chem. Phys., subrnitted.

304. "Metastable Unimolecular and Collision-Induced Dissociation of Hydrogen-Bonded Clusters: Evidence for Intracluster Molecular Rearrangement and the Structure of Solvated Protonated Complexes," S. Wei, W. B. Tzeng, and A. W. Castleman, Jr., J. Am. Chem. Soc., submitted.*

305. "General Discussion on Large Gas-Phase Clusters," A. W. Castleman, Jr., J. Chem. Soc. Faraday Trans. 86, 2389, 2452-55, 249, 2522 (1990).* 


\section{BIBLIOGRAPHY}

1. A. W. Castleman, Jr. and R. G. Keesee, Science, 241, 36 (1988).

2. A. W. Castleman, Jr. and R. G. Keesee, Ann. Rev. Phys. Chem., 37, 525 (1986).

3. A. W. Castleman, Jr. and R. G. Keesee, Accts. Chem. Res., 19, 413 (1986)

4. Large Finite Systems, Vol. 20 (J. Jortner, A. Pullman, and B. Pullman, Eds.) D. Reidel Publishing Company (1987).

5. Physics and Chemistry of Small Clusters (P. Jena, B. K. Rao and S. N. Khanna, Eds.) NATO ASI Series, Vol. 158 (1987).

6. A. W. Castieman, Jr., T. D. Märk, in Gaseous Chemistry and Mass Spectrometry (J. H. Futrell, eci.) Wiley-Interscience, New York, p. 259 (1986).

7. A. W. Castleman, Jr. and R. G. Keesee, Chem. Rev., 86, 589 (1986).

8. (a) Elemental and Molecular Clusters (G. Benedek, T. P. Martin, and G. Pacchioni, Eds.) Springer-Verlag (1988). (b) Surface Science, Vol. 156, Part 1 and Part 2 (1985).

9. T. D. Mårk and A. W. Castleman, Jr., in Adv. Atomic Molecular Phys., 20, 65 (1984).

10. P. Schuster, P. Wolschann, and K. Tortschanoff, "Dynamics of Proton Transfer in Solution," in Chemical Relaxation in Molecular Biology (I. Pecht and R. Rigler, Eds.) Springer-Verlag, pp. 107-190 (1977).

11. N. E. Gaecintov and M. Pope, "Photophysical Studies of Polycyclic Aromatic Mutagens and Their Interactions with DNA, 23rd DOE Radiological and Chemical Contractors' Meeting, Berkeley, CA, June 26-28, 1990.

12. (a) M. Kasha, "Competitive Molecular Excitation Mechanisms: Intramolecular Proton-Transfer and Twisting-Intramolecular Charge-Transer and Their Applications," 23rd DOE Radiological and Chemical Contractors' Meeting, Berkeley, CA, June 26-28, 1990; (b) J. Heldt, D. Gormin, M. Kasha, Chem. Phys. 136, 321 (1989); (c) D. Gormin, J. Heldt, M. Kasha, J. Phys. Chem. 94, 1185 (1990).

13. A. M. Findley, S. P. McGlynn, G. L. Findley, The Geometry of Genetics, John Wiley \& Sons (1989).

14. J. L. Magee and A. Chatterjee, "Trace Reactions of Radiation Chemistry," in Kinetics of Nonhomogeneous Processes (G. R. Freeman, Ed). John Wiley Sons, Chapt. 4, pp. 171-214, (1987). 
15. (a) R. N. Compton, C. E. Klots, H. S. Carman, Jr., and J. C. Miller, "Chemical Physics Studies of the Gaseous and Condensed Phases Using Pulsed Lasers," 23rd DOE Radiological and Chemical Contractors' Meeting, Berkeley, CA, June 26-28, 1990; (b) H. S. Carman, Jr., C. E. Klots, and R. N. Compton, "Charge-Exchange Studies Between Highly Excited Atoms and Ultracold Molecules and Clusters," Ibid.; (c) R. Katz, "Theory of RBE," Ibid.; (d) J. S. Muenter, "Intermolecular Potential Functions From Spectroscopic Studies of Molecular Clusters, Ibid.

16. A. W. Castleman, Jr., Environ. Sci. Tech. 22, 1265 (1988).

17. (a) Environmental Chemistry Division Annual Report, Report No. BNL 39542, January (1987). (b) Y.-N. Lee, J. Shen, P. J. Klotz, S. E. Schwartz and L. Newman, J. Geophys. Res. 91, 13264 (1986). (c)T. Novakov, in Heterogeneous Atmospheric Chemistry (D.R. Schryer, Ed) American Geophysical Union, pp. 215-220 (1982); T. Novakov, LBL-17073 (Excerpt B), September 1984. (d) M. J. Rossi, R. Malhotra, D. M. Golden, Geophys. Res. Lett. 14, 127 (1987). (e) M. Pope and N. E. Geacintov (see Ref. 17 (h), \#94). (f) Programs of L. G. Christophorou, T. N. Compton, C. E. Klots, and J. C. Miller in the Chemical Physics Section of the Health and Safety Research Division of the Oak Ridge National Laboratory as described in "Research in Progress: FY 1984," DOE/ER-0185, December 1983, Nat. Tech. Inf. Service, Springfield, VA. (g) Programs of P. M. Dehmer and J. L. Dehmer, as described in "Radiological and Environmental Research Division Annual Report," ANL-82-65, Part I, Nat. Tech. Inf. Service, Springfield, VA. (h) J. S. Gaffney, BNL 5160, April 1982, Nat. Tech. Inf. Service, Springfield, VA.; DOE/ER-0185/3, Ibid.

18. T. Suzuki, M. Hiroi, and M. Ito, J. Phys. Chem. 92, 3774 (1988).

19. P. D. Dao, S. Morgan, and A. W. Castleman, Jr., Chem. Phys. Lett., 111, 38 (1984).

20. P. D. Dao, S. Morgan, and A. W. Castleman, Jr., Chem. Phys. Lett., 113, 219 (1985).

21. E. R. Bernstein and J. Lee, J. Chem. Phys. 74, 3159 (1981).

22. Y. Saito, K. Kamauchi, K. Mihama, and T. Noda, Jap. J. Appl. Phys. 21, L396 (1982).

23. K. Sattler, Surface Sci., 156, 292 (1985).

24. E. A. Neubert, High Temp. Sci. 10, 261 (1978).

25. T. P. Martin, Phys. Rep. 95, 167 (1983).

26. W. A. Saunders, Phys. Rev. B. 37, 6583 (1988).

27. R. Pflaum, P. Pfau, K. Sattler and E. Recknagel, Surface Science 156, 165 (1985).

28. S. Sasaki, K. Fujino, Y. Takeuchi, and R. Sadanaga, Acta Crys. A36, 904 (1980).

29. C. Lifshitz and F. Louage, J. Phys. Chem. 93, 5633 (1989).

30. P. C. Engelking, J. Chem. Phys. 85, 3103 (1986). 
31. P. C. Engelking, J. Chem. Phys. 87, 936 (1987).

32. (a) M. T. Bowers, T. Su, V. G. Anicich, J. Chem. Phys. 58, 5175 (1973). (b) L. M. Bass, R. D. Cates, M. F. Jarrold, N. J. Kirchner, and M. T. Bowers, J. Am. Chem. Soc. 105, 7824 (1983).

33. S. T. Grual and R. R. Squires, Int. J. Mass Spectrom. Ion Proc. 81, 183 (1987).

34. T. F. Morton, Tetrahedron Lett. 137, 3195 (1982).

35. R. G. Keesee and A. W. Castleman, Jr., J. Phys. Chem. Ref. Data 15, 1011 (1986).

36. S. Morgan and A. W. Castleman, Jr., J. Am. Chem. Soc. 109, 2868 (1987).

37. E. P. Grimsrud and P. Kebarle, J. Am. Chem. Soc. 95, 7939 (1973).

38. M. S. B. Munson, J. Am. Chem. Soc., 87, 5313 (1965).

39. A. S. Blair and A. G. Harrison, Can. J. Chem., 15, 703 (1973).

40. Z. Luczynski and H. Wincel, Int. J. Mass Spectrom. Ion Phys., 23, 37 (1977).

41. L. W. Sieck and P. Ausloos, Radiat. Res., 52, 47 (1972).

42. K. A. G. MacNeil and J. H. Futrell, J. Phys. Chem., 76, 409 (1972).

43. A. J. Stace and A. K. Shukla, J. Phys. Chem., 86, 865 (1982).

44. J. K. Terlouw, W. Heerma, and J. L. Holmes, Org. Mass Spectrom., 16, 306 (1981).

45. R. H. Nobes, W. J. Bouma and L. Radom, J. Am. Chem. Soc., 105, 309 (1983).

46. P. Sykes, A Guide Book to Mechanism in Organic Chemistry, 5th Edition, p. 221, Longman Group Ltd., New York (1981).

47. Y. K. Lau, P. P. S. Saluja, and P. Kebaele, J. Am. Chem. Soc., 102, 7429 (1980)

48. K. Hiraoka, E. P. Grimsrud, and P. Kebarle, J. Am. Chem. Soc., 96, 3359 (1974)

49. I. N. Tang and A. W. Castleman, Jr., J. Chem. Phys. 62, 4576 (1975)

50. S. G. Lias, J. F. Liebman, and R. D. Levin, J. Phys. Chem. Ref. Data, 13, 695 (1984)

51. F. H. Westheimer, Science 235, 1173 (1987),

52. F. H. Westheimer, Chem. Rev. 81, 313 (1981). 
53. (a) Ye. B. Rudnyi, Deposited Doc., VINITI 7085-83, Pt. 1, 100-3 (1983); (b) L. N. Sidorov, E. B. Rudnyi, M. I. Nikitin, I. D. Sorokin, Dokl. Akad. Nauk SSSR 272, 770 (1983) Engl. transl.; (c) E. B. Rudnyi, O. M. Vovk, L. N. Sidorov, I. D. Sorokin, A. S. Alikhanyen, High Temp. 24, 56 (1986) Engl. transl.

54. W. Unkel and A. Freedman, AIAA J. 21, 1648 (1983).

55. L. L.Lohr and R. C. Boehm, J. Phys. Chem. 91, 3203 (1987).

56. I. P. Beletskii and K. B. Yatsimirskii, Zh. Obshch. Khim. 56, 35 (1986) (Engl. transl. p. 29).

57. M. Henchman, A. A. Viggiano, J. F. Paulson, A. Freedman, and J. Wormhoudt, J. Am. Chem. Soc. 107, 1453 (1985).

58. (a) W. P. Jencks, Acc. Chem. Res 13, 161 (1980). (b) F. Ramirez, J. Marecek, J. Minore, S. Srivastava, W. leNoble, J. Am. Chem. Soc. 108, 348 (1986). (c) J. Burgess, N. Blundell, P. M. Cullis, C. D. Hubbard, R. Misra, J. Am. Chem. Soc. 110, 7900 (1988). (d) S. Freeman, J. M. Friedman, J. R. Knowles, J. Am. Chem. Soc. 109, 3166 (1987). (e) P. M. Cullis and D. Nicholls, J. Chem. Soc. Chem. Comm., 783 (1987).

59. W. Burgermeister and R. Winkler-Oswatitsch, Top. Curr. Chem. 69, 91 (1977).

60. D. N. Hague, Mol. Biol. Biochem. Biophys. 84 (1977).

61. C. J. Pederson, J. Am. Chem. Soc. 89, 2495 (1967).

62. W. R. Davidson and P. Kebarle, Can. J. Chem. 54, 2594 (1976).

63. A. T. Tsatsas, R. W. Stearns and W. M. Risen, Jr., J. Am. Chem. Soc. 94, 5247 (1972).

64. K. Kistenmacher, H. Popkie and E. Clementi, J. Chem. Phys. 61, 799 (1974).

65. D. H. Haynes, B. C. Pressman and A. Kowalsky, Biochem. 10, 852 (1971).

66. B. T. Kilbourn, J. D. Dunitz, L. A. R. Pioda and W. Simon, J. Molec. Biol. 30, 559 (1967).

67. J. L. Durant, D. M. Rider, S. L. Anderson, F. D. Proch, R. N. Zare, J. Chern. Phys. 80, 1817 (1984).

68. P. D. Dao and A. W. Castleman, Jr., J. Chem. Phys. 84, 1435 (1986).

69. S. T. Ceyer, P. W. Tiedemann, B. H. Mahan, and Y. T. Lee, J. Chern. Phys. 70, 14 (1979).

70. R. D. Levin and S. G. Lias, Ionization Potential and Appearance Potential Measurements 1971-1981, NSRDS-NBS 71 (1982).

71. J. J. Breen, W.-B. Tzeng, K. Kilgore, R. G. Keesee and A. W. Castleman, Jr., J. Chem. Phys. 90,19 (1989). 
72. D. Smith and N. G. Adarns, Astrophys. J. 217, 741 (1977); W. Lindinger, D. L. Albritton, F. C. Fehsenfeld, A. L. Schmeltekopf and E. E. Ferguson, J. Chem. Phys. 62, 3549 (1975).

73. R. S. Hemsworth, J. D. Payzant, H. I. Schiff and D. K. Bohme, Chem. Phys. Lett. 26,417 (1974).

74. R. G. Keesee and A. W. Castleman, Jr., J. Phys. Chem. Ref. Data 15, 1011 (1986).

75. N. E. Levinger, D. Ray, M. L. Alexander, and W. C. Lineberger, J. Chem. Phys. 89, 5654 (1988).

76. Y. Nachson, F. K. Tittel, W. L. Wilson, Jr., and W. L. Nighan, J. Appl. Phys. 56, 36 (1984).

77. W. L. Nighan, R. A. Sayerbergy, Y. Zho, F. K. Tittel, and W. L. Wilson, Jr., IEEE J. Quant. Elect. QE-23, 253 (1987).

78. D. E. Hunton, M. Hofmann, T. G. Lindeman, and A. W. Castleman, Jr., J. Chem. Phys. 87, 5043 (1987).

79. O. Echt, M. C. Cook, and A. W. Castleman, Jr., Chem. Phys. Lett., 135, 229 (1987).

80. O. Echt, P. D. Dá, S. Morgan, and A. W. Castleman, Jr., J. Chem, Phys., 82, 4076 (1985).

81. C. E. Klots, J. Chem. Phys., 83, 5854 (1985).

82. C. E. Klots, Z. Phys. D, 5, 83 (1987).

83. C. E. Klots, Chem. Phys. Lett., 10, 422 (1971). 
Table I. The abundance maxima observed in the mass spectra of (MgO) ${ }^{+}$and 51 $(\mathrm{MgO}) \mathrm{Mg}^{+}$clusters and proposed structures based on the face-centered cubic structure of crystaliline $\mathrm{MgO}$.

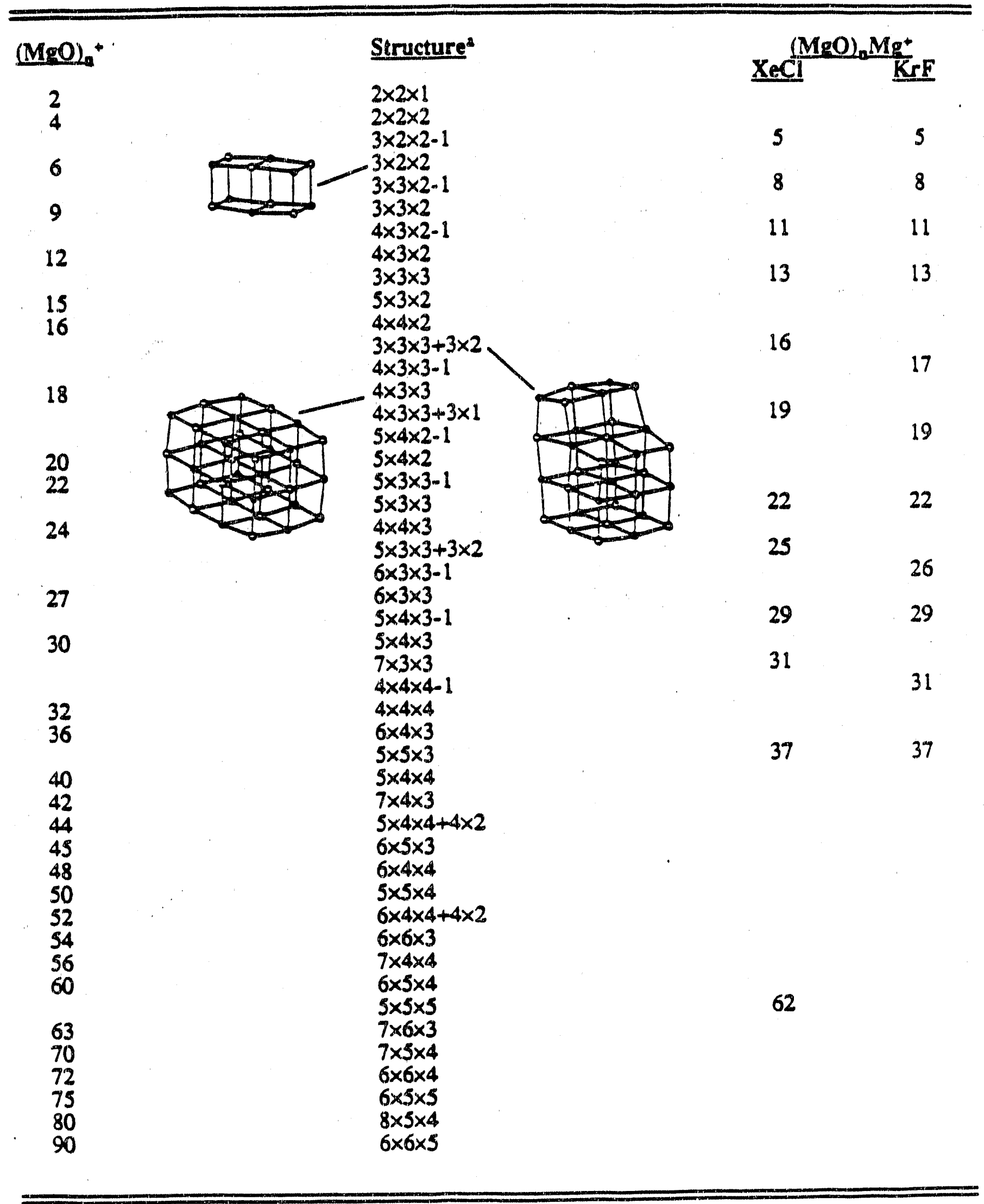

The axbxc designation corresponds to a cubic suructure with $a, b$, and $c$ atoms along each edge, and when followed by -1 corresponds to the given structure with a missing $\mathrm{O}$ atom. 
Table II

\section{Unimolecular Dissociation Reactions}

Pure Ammonia Clusters

$$
\left(\mathrm{NH}_{3}\right)_{\mathrm{m}} \mathrm{H}^{+} \rightarrow\left(\mathrm{NH}_{3}\right)_{\mathrm{m}-1} \mathrm{H}^{+}+\mathrm{NH}_{3} \quad \square 0
$$

Pure Acetone Clusters

$$
\begin{aligned}
& \mathrm{CH}_{3} \mathrm{CO}^{+} \rightarrow\left(\mathrm{CH}_{3} \mathrm{CO}\right)^{+} \mathrm{T}_{\mathrm{n}-1}+\mathrm{T} \quad \Delta \\
& \left(\mathrm{CH}_{3} \mathrm{CO}\right)^{+} \mathrm{T}_{\mathrm{n}} \rightarrow \mathrm{CH}_{3} \mathrm{COT}_{\mathrm{n}-1}+\mathrm{T} \quad \Delta \\
& \mathrm{T}_{1} \mathrm{H}^{+} \rightarrow\left(\mathrm{CH}_{3} \mathrm{COH}\right)^{+}+\mathrm{CH}_{3} \Delta \Delta \\
& \rightarrow(\mathrm{COH})^{+}+2 \mathrm{CH}_{3} \quad \Delta \\
& \mathrm{T}_{\mathrm{n}}^{+} \rightarrow \mathrm{T}_{\mathrm{n}-1}^{+}+\mathrm{T} \\
& \mathrm{T}_{\mathrm{n}} \mathrm{H}^{+} \rightarrow \mathrm{T}_{\mathrm{n}-1} \mathrm{H}^{+}+\mathrm{T}
\end{aligned}
$$

$\Delta$

$\Delta$

$\Delta$

$\Delta$

\section{Mixed Clusters}

$$
\begin{array}{ll}
\mathrm{T}_{\mathrm{n}} \mathrm{NH}_{3}{ }^{+} \rightarrow \mathrm{T}_{\mathrm{n}}^{+}+\mathrm{NH}_{3} & \square \\
\mathrm{T}_{\mathrm{n}} \mathrm{NH}_{4}{ }^{+} \rightarrow \mathrm{T}_{\mathrm{n}-1} \mathrm{NH}_{4}^{+}+\mathrm{T} & \square \Delta \mathrm{O} \\
\mathrm{T}_{\mathrm{n}}\left(\mathrm{NH}_{3}\right)_{\mathrm{m}}^{+} \rightarrow \mathrm{T}_{\mathrm{n}}\left(\mathrm{NH}_{3}\right)_{\mathrm{m}-1}^{+}+\mathrm{NH}_{3} & \square \\
\mathrm{T}_{\mathrm{n}}\left(\mathrm{NH}_{3}\right)_{\mathrm{m}} \mathrm{H}^{+} \rightarrow \mathrm{T}_{\mathrm{n}}\left(\mathrm{NH}_{3}\right)_{\mathrm{m}-1} \mathrm{H}^{+}+\mathrm{NH}_{3} & \square \mathrm{O}
\end{array}
$$

$\square$ Coexpansion

O Ammonia from side

$\Delta$ Acetone from side 


\section{Ion Dip Spectroscopy}

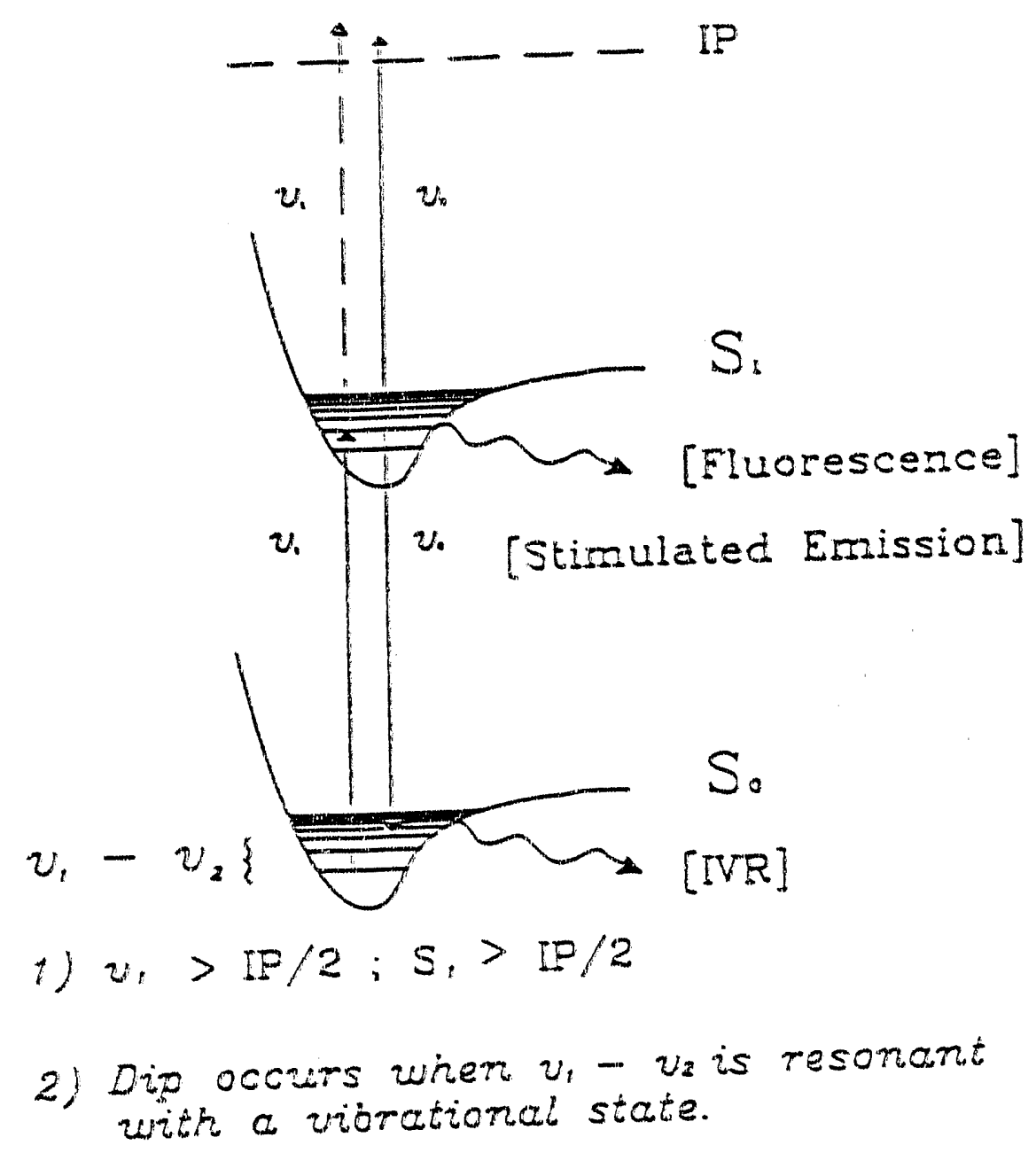

Figure 1. Schematic representation of lon dip spectroscopy. The pump
photon $\omega_{1}$ determines which vibronic stace is populated in $S_{1}$, Note photon $\omega_{1}$ determines whoth photon $\omega_{2}$ is responsible for both jonization and stimulated emission. 
Ion Dip Spectrum of PA
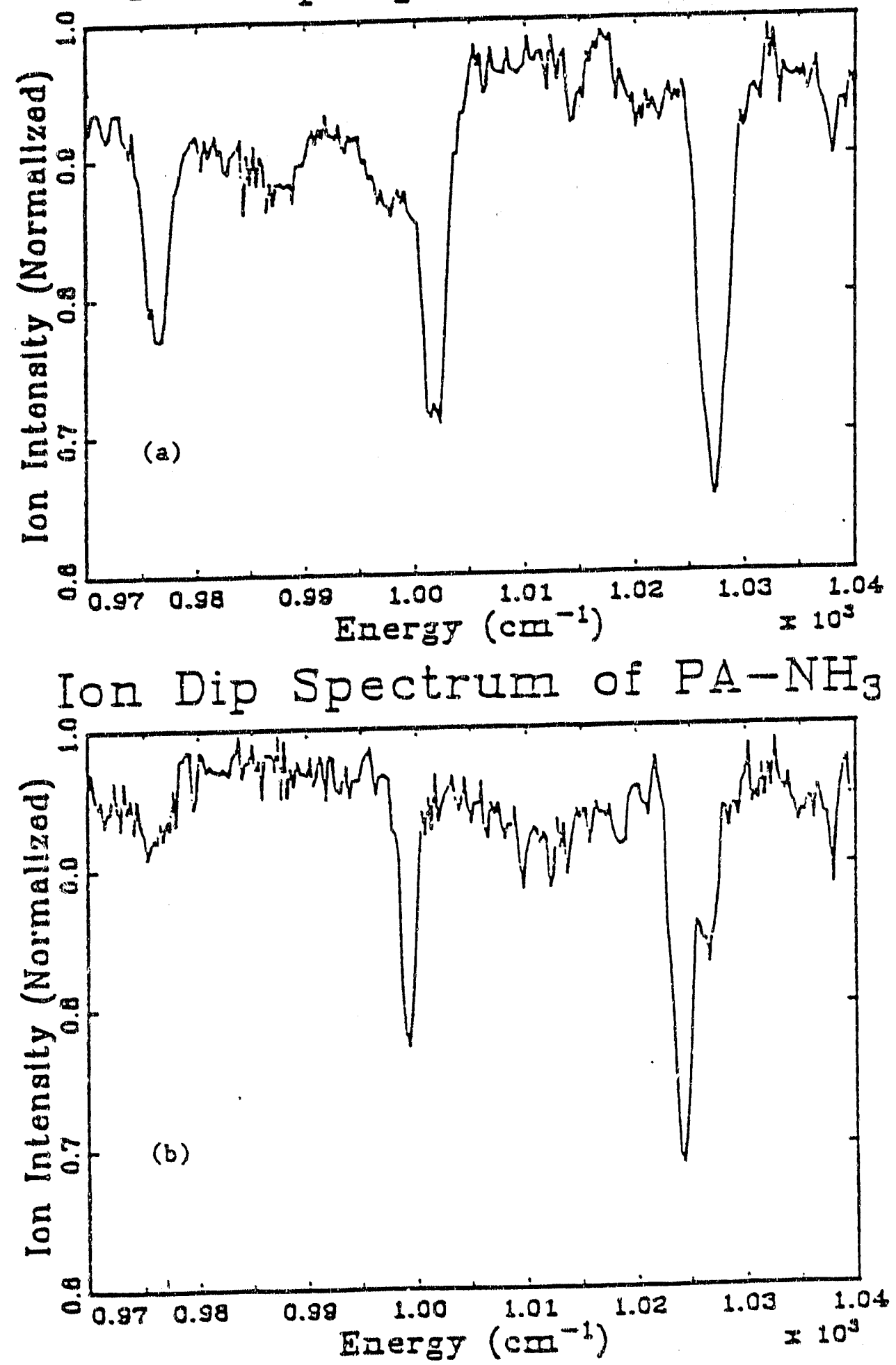

Figure 2. (a) Ion dip ppectrum of phenylacetylene from $35_{0}^{1}$ in $\mathrm{S}_{1}$ to $\mathrm{S}_{0}$. $w_{1}$ is set to the $35_{0}$ in $S_{1}$ and $w_{2}$ is scanned such that stimulated emission occurs over the range of $900-1100 \mathrm{~cm}^{-1} \mathrm{~cm}-1$, representing the electronic red shift of the $v_{35}$ vibronic band in $S_{1}$ due to the $\mathrm{NH}_{3}$ ligand. 


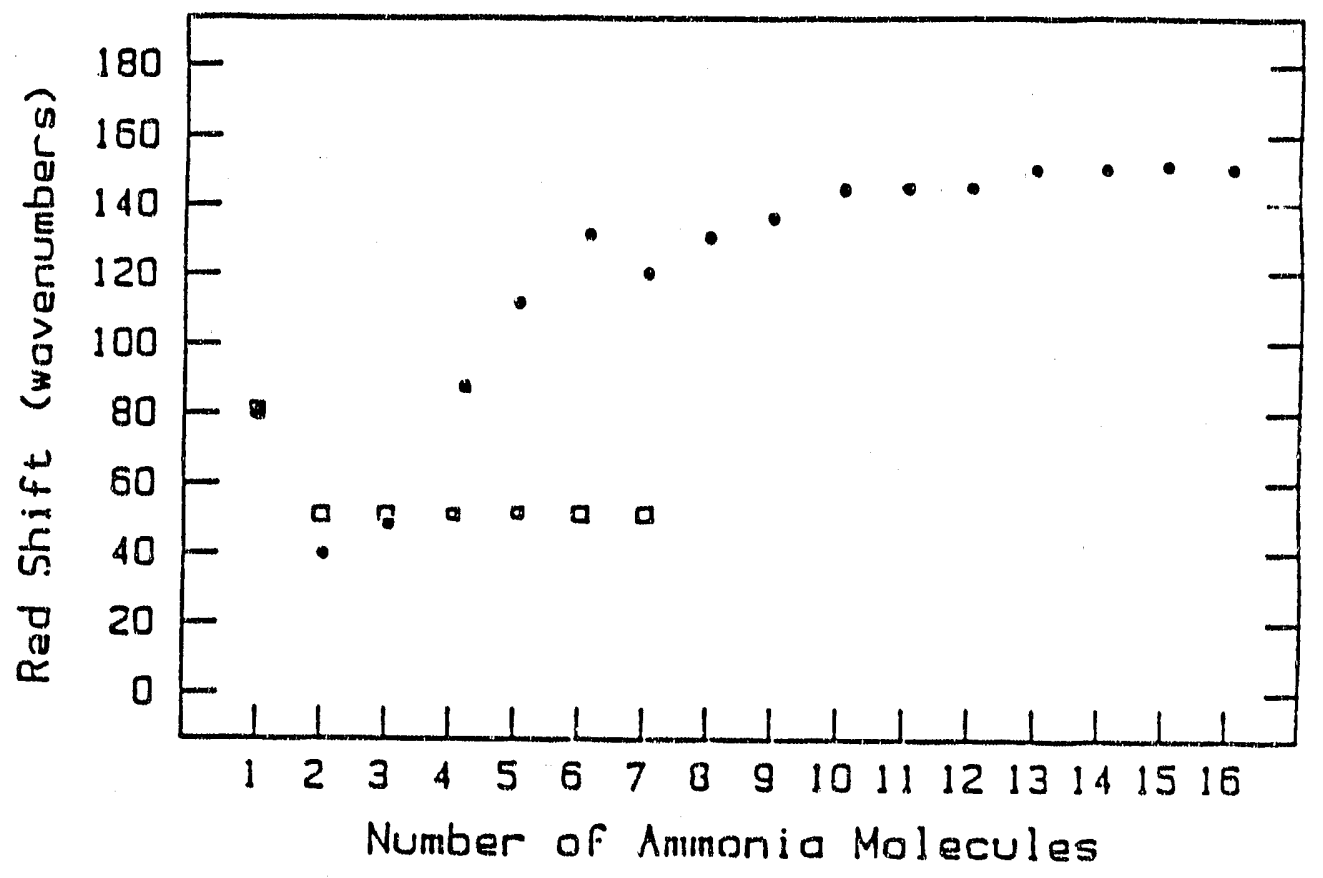

Figure 3. Linear plot of the specrral shifts for $\mathrm{PA}\left(\mathrm{NH}_{3}\right)_{n}$ cluster made in coexpansion experiments $(\square)$ the cluster attachment experiments (*). 

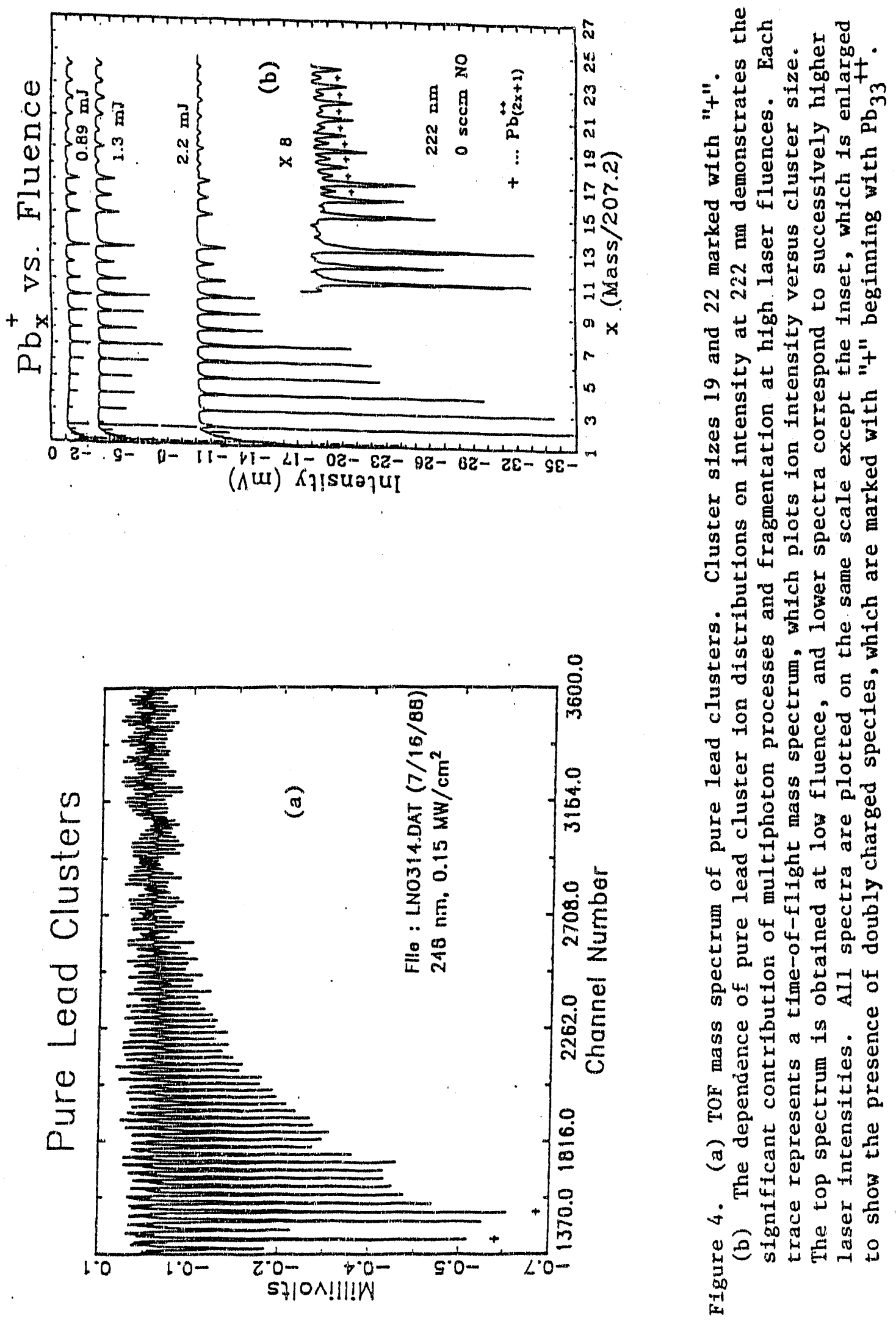


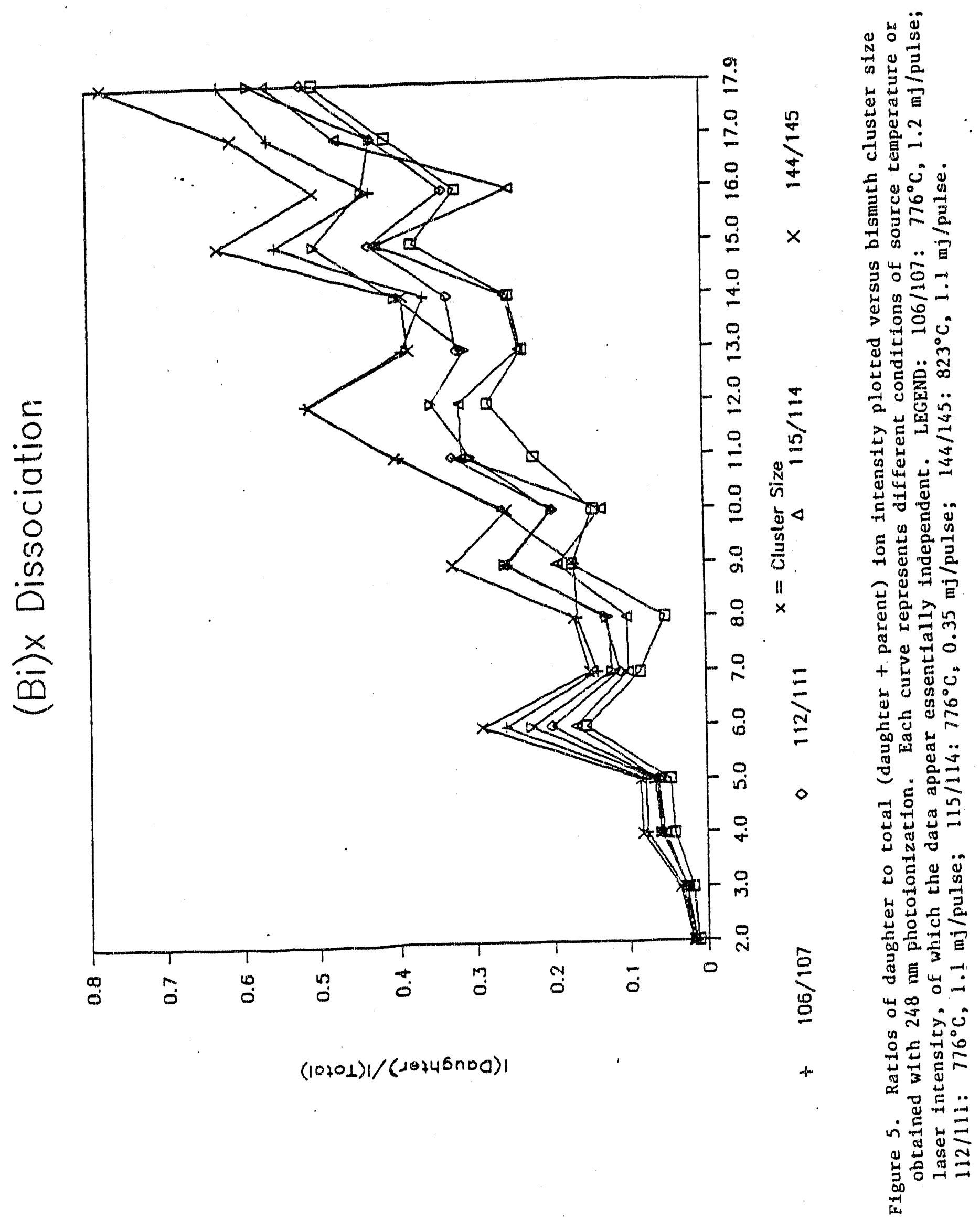



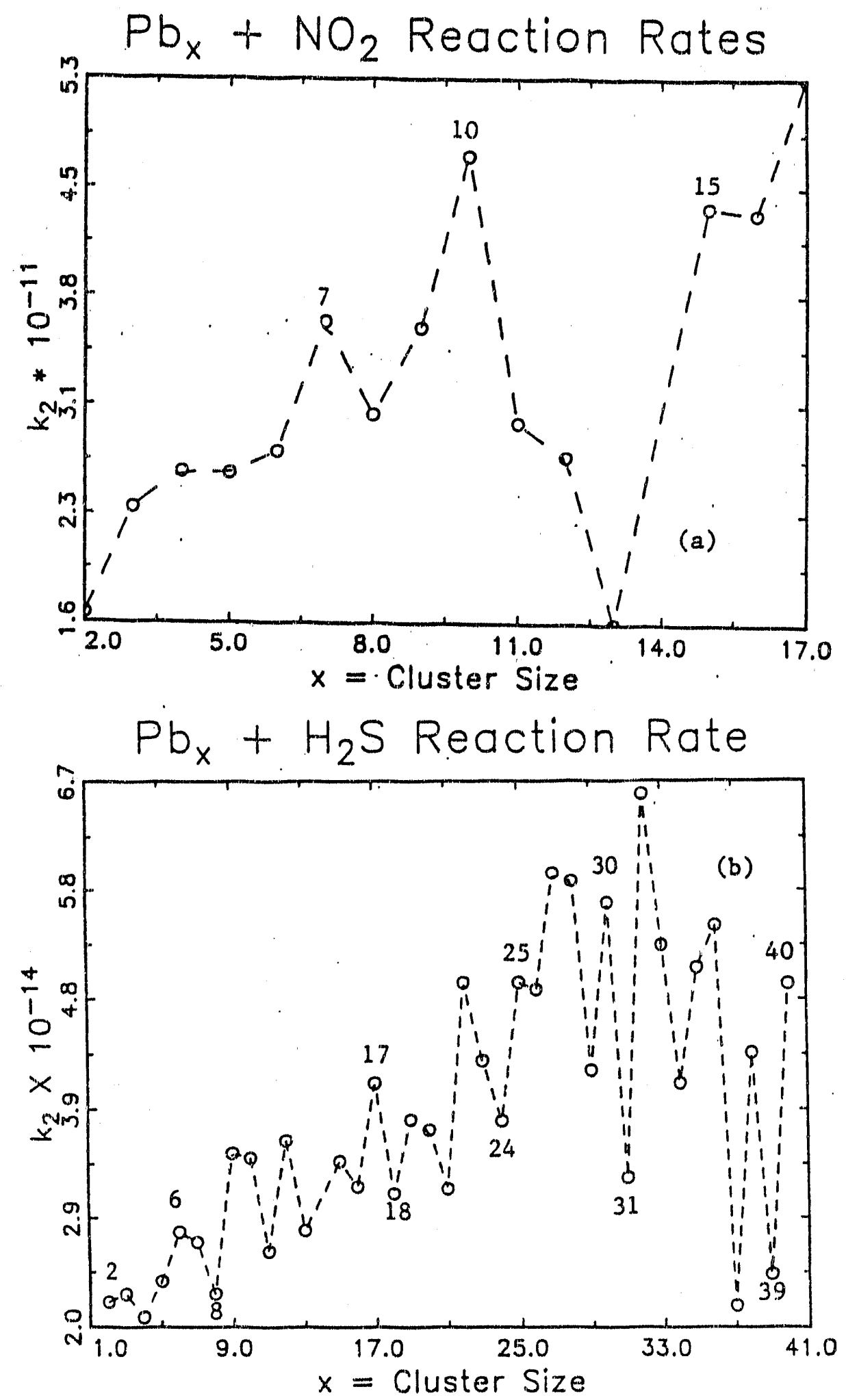

Figure 6. (a) Lead cluster $+\mathrm{Cl}_{2}$ reaction rates. Ionization by $222 \mathrm{~nm}$, $1.5 \mathrm{mj} / \mathrm{cm}^{2}$ radiation. (b) Lead clusters $+\mathrm{H}_{2} \mathrm{~S}$ reaction rates. Ionization by $222 \mathrm{~nm}, 3 \mathrm{mj} / \mathrm{cm}^{2}$ radiation. 


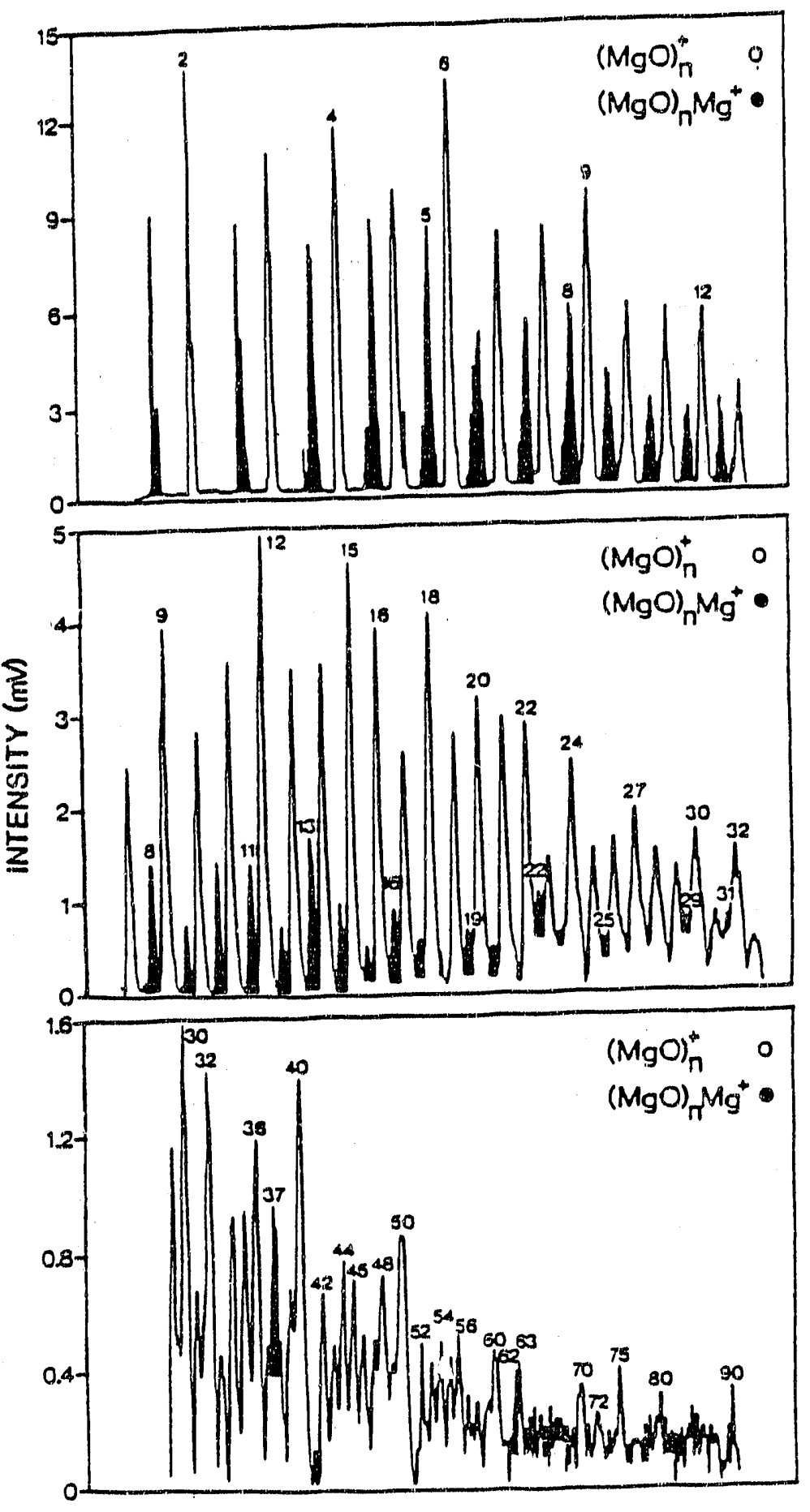

Figure 7. Mass spectra of $(\mathrm{MgO})_{\mathrm{n}}{ }^{+}$and $(\mathrm{MgO})_{\mathrm{n}} \mathrm{Mg}^{+}$clusters obtained by using $308 \mathrm{~nm}$ wavelength radiation for ionization ( $\mathrm{XeCl}$ excimer gas, $4.03 \mathrm{eV}$ photons, $45 \mathrm{~mJ} / \mathrm{pulse}$ ) and source conditions optimized for different cluster size regimes. The bottom two are portions of the same mass spectrum. 


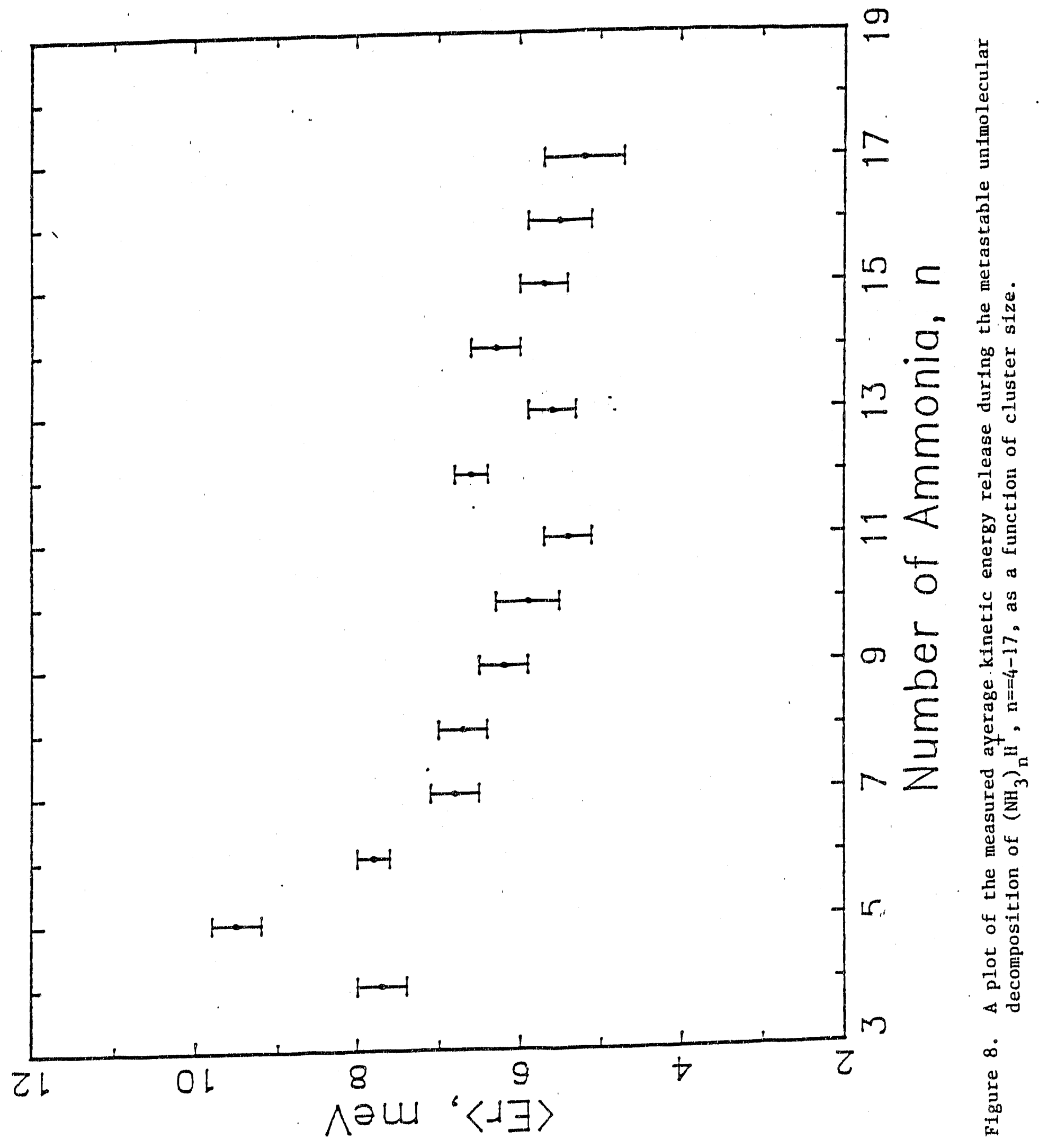

${ }^{\mathrm{i}} \mathrm{:}$ 


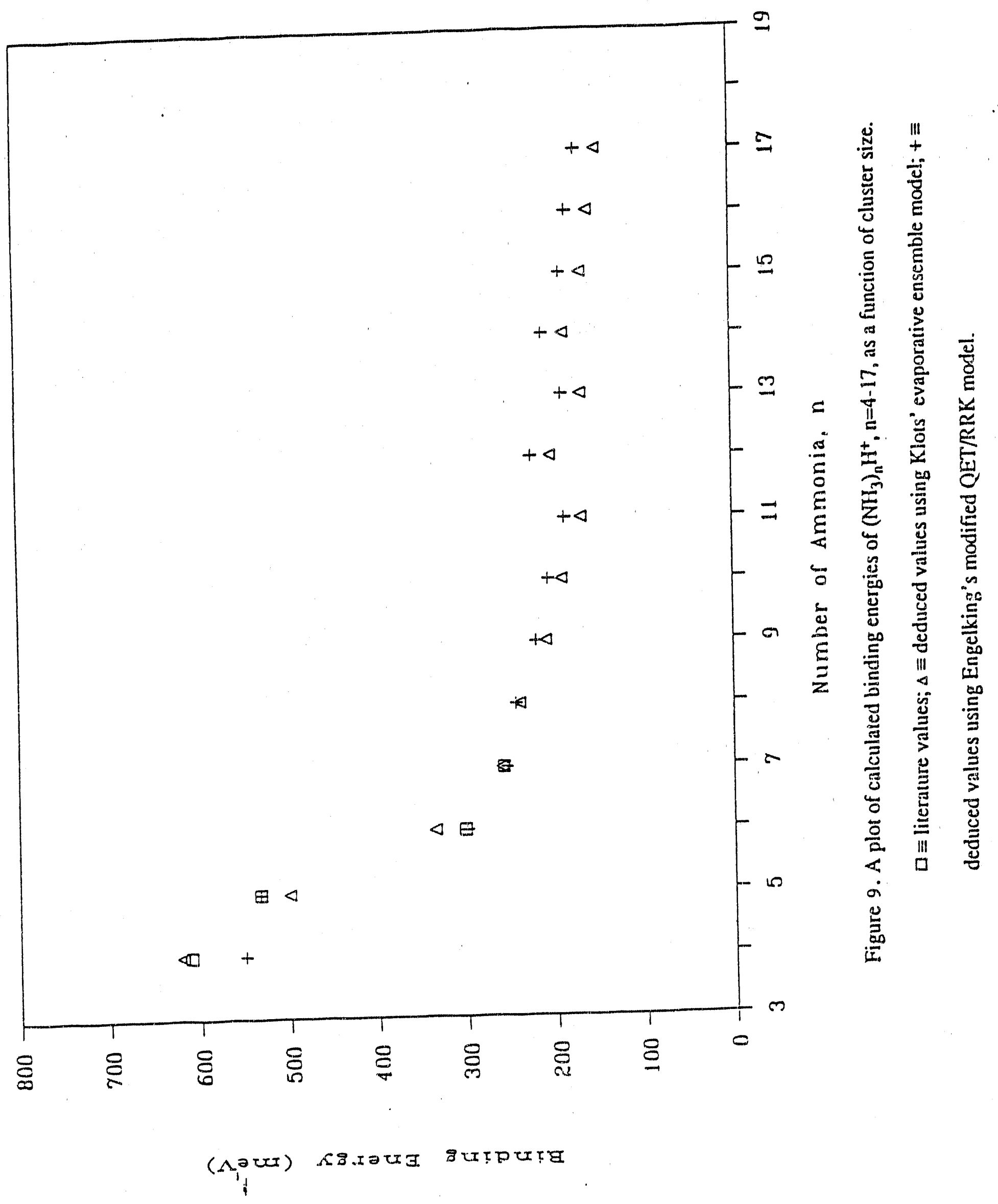




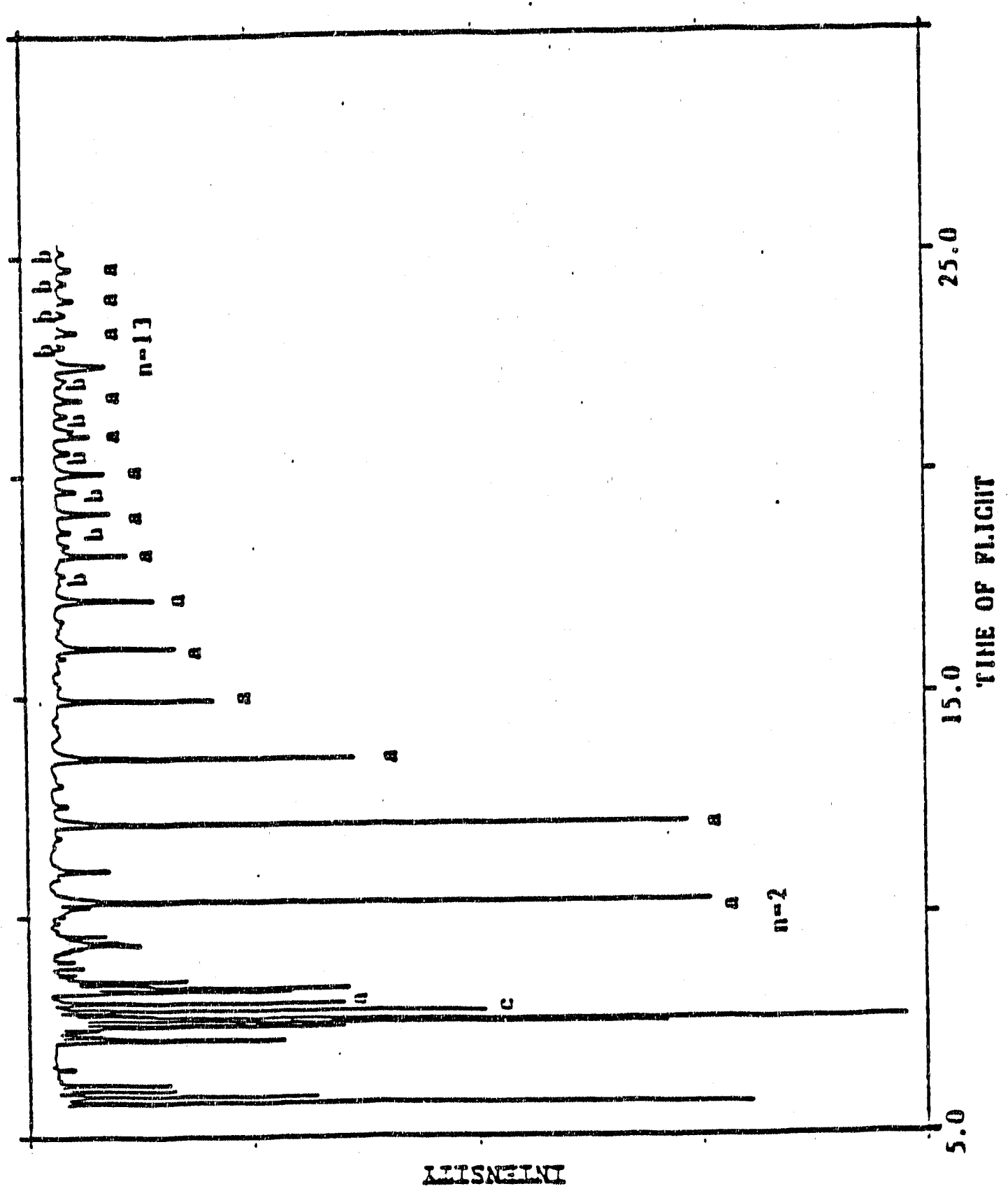

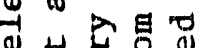

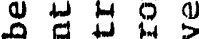

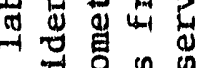

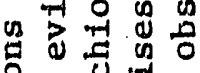

की

건엉을

出出出 $九$

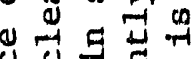

एक त्र

虽

ه चु

$\underset{0}{=}$

응 चु

E

ค 넝

- 告

क \&

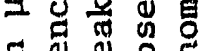

击寻吕

品《品

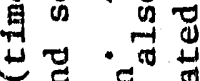

业

号至出

i $0_{0}$.

क खीं

穴 40

- $\widehat{0} \stackrel{\Delta}{ }$

IND

ฮี

番形

O)

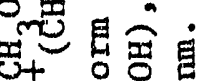

计

+国出罢 出告造是

曾每出

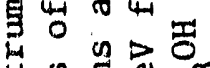

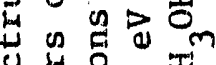
过 워 थ a t in

の $0 \begin{aligned} & 4 \\ & 0\end{aligned}$

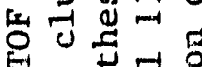

-1 -

- Q के

0 更

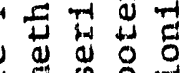

㟧界界

.

in 

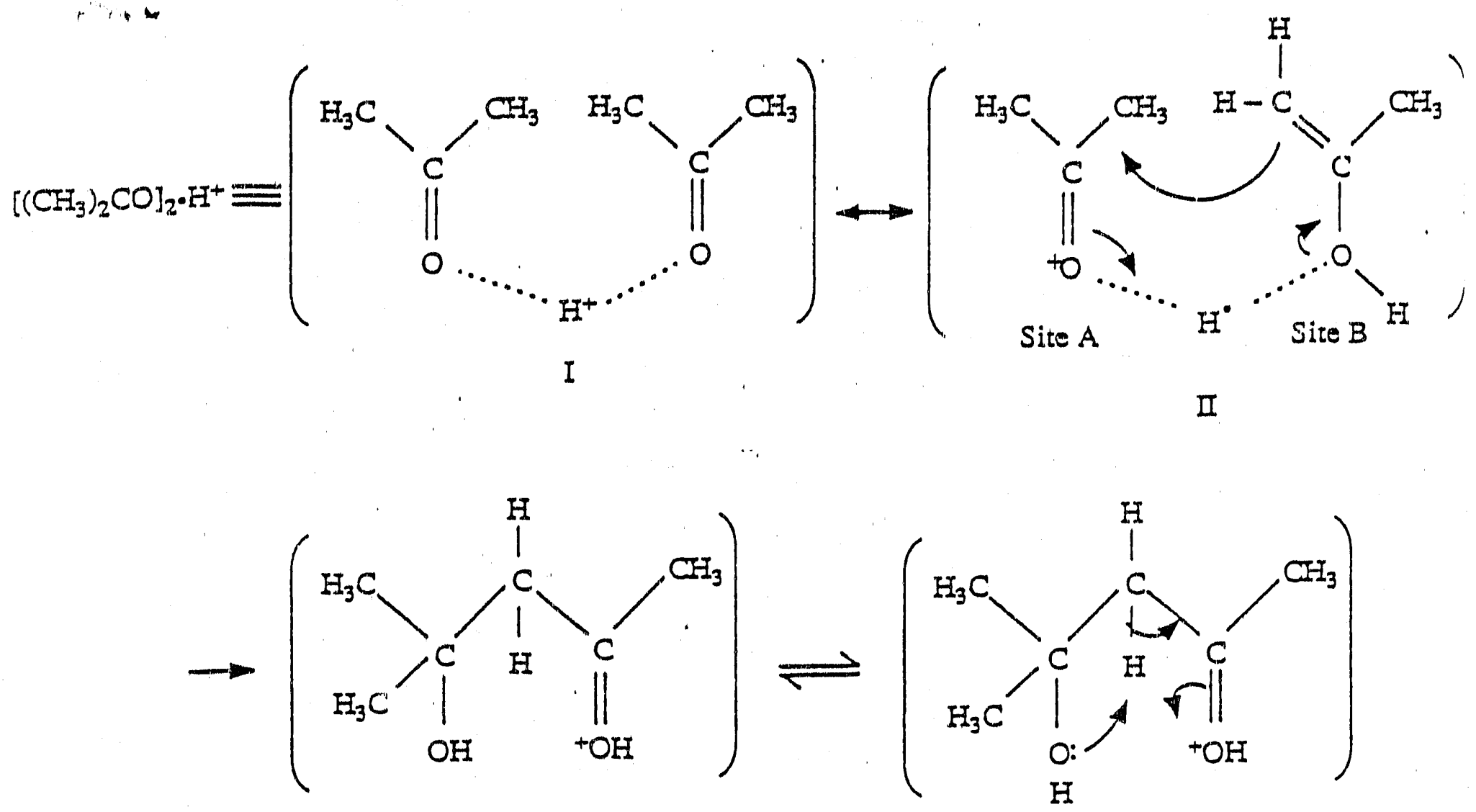

III

IV

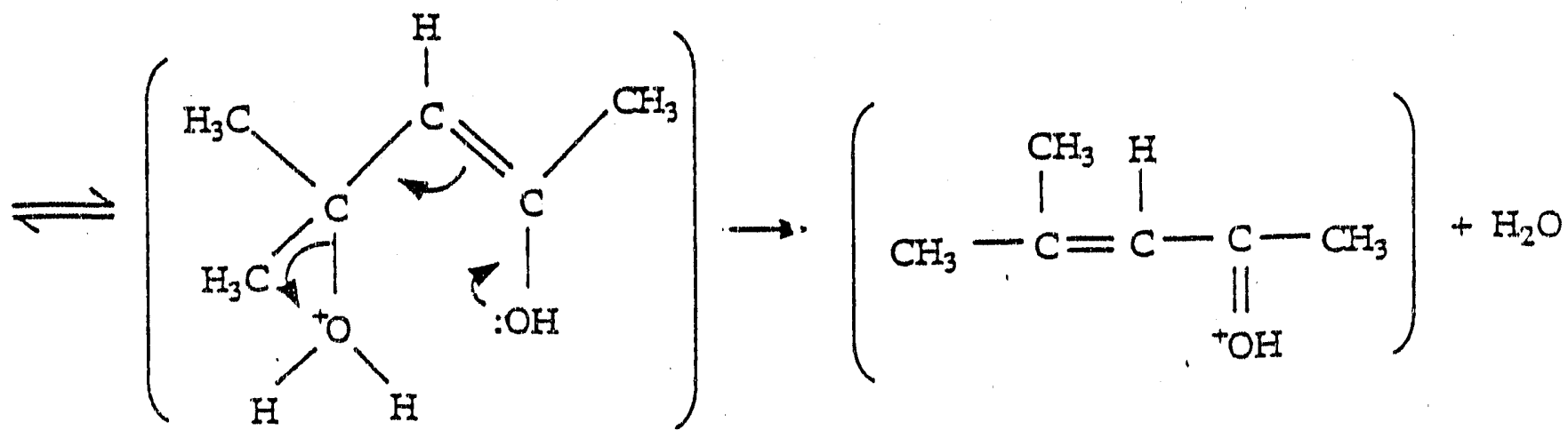

VI, $\mathrm{C}_{6} \mathrm{H}_{! 1} \mathrm{O}^{+}$

Figure 11. The structure of protonated acetone dimer (i) can be written as a combination of ketone and enol forms, as shown in structure II. The protonated acetone dimer undergoes a common water elimination reaction through intermediate species III-V to yield the protonated mesityl oxide, $\mathrm{C}_{6} \mathrm{H}_{11} \mathrm{O}^{+}$(VI). When water is present in the system, it can bond to either site $A$ or site $B$. However, the dhydration reaction of the protonated acetone cluster is quenched if the water molecule is bonded to site A in structure II. As a result, the dehydration reaction of the protonated acetone cluster 1s quenched. By contrast, another acetone moiecule would only bond to site $\mathrm{B}$. 

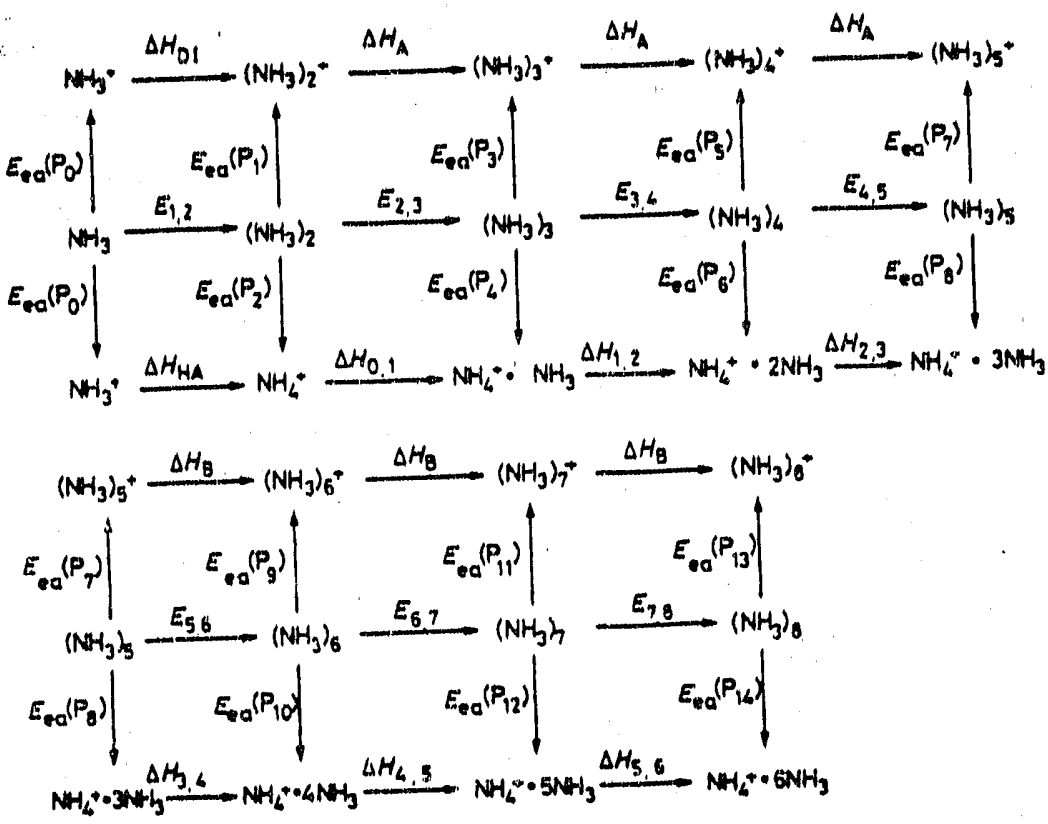

(a)

\begin{tabular}{|c|c|c|c|}
\hline renction & $\begin{array}{l}\text { relurence } \\
\text { value/eV }\end{array}$ & reaction & $\begin{array}{l}\text { reference } \\
\text { value/eV }\end{array}$ \\
\hline $\begin{array}{l}E_{A}\left(P_{0}\right) \\
E_{1,2} \\
E_{1,3} \\
E_{3,4} \\
E_{4,3} \\
E_{5,4} \\
E_{6,7} \\
E_{9,4} \\
\Delta H_{0,} \\
\Delta H_{\wedge} \\
\Delta H_{1} \\
\Delta H_{M,} \\
\Delta H_{0,1} \\
\Delta H_{1,2} \\
\Delta H_{2,3} \\
\Delta H_{3,4} \\
\Delta H_{4,3} \\
\Delta H_{5,0}\end{array}$ & $\begin{array}{l}10.166^{\circ} \\
0.13^{4} \\
0.24^{\circ} \\
0.20^{\circ} \\
0.17^{\circ} \\
0.25^{\circ} \\
0.25^{\circ} \\
0.25^{\circ} \\
-0.79 \pm 0.5^{\circ} \\
-0.5 \pm 0.2^{\circ} \\
-0.3^{\circ} \\
-0.7 \pm 0.4^{\circ} \\
-1.10^{4} \\
-0.76^{4} \\
-0.62^{d} \\
-0.51^{\prime \prime} \\
-0.34^{d} \\
-0.28^{d}\end{array}$ & 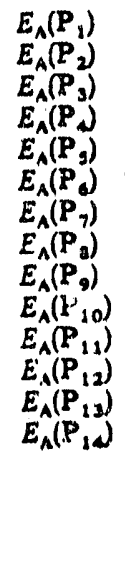 & $\begin{array}{l}9.54 \\
9.59 \\
9.28 \\
8.73 \\
8.98 \\
8.17 \\
8.65 \\
7.72 \\
8.60 \\
7.46 \\
8.55 \\
7.37 \\
8.50 \\
7.34\end{array}$ \\
\hline
\end{tabular}

(b)

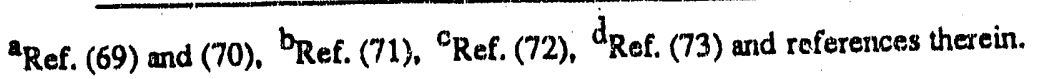

Figure 12. (a) Thermochemical Born-Haber cycle related to the ammonia cluster system discussed in the text. (b) Thermodynamic values pertinent to the Born-Haber Cycle for (a). 

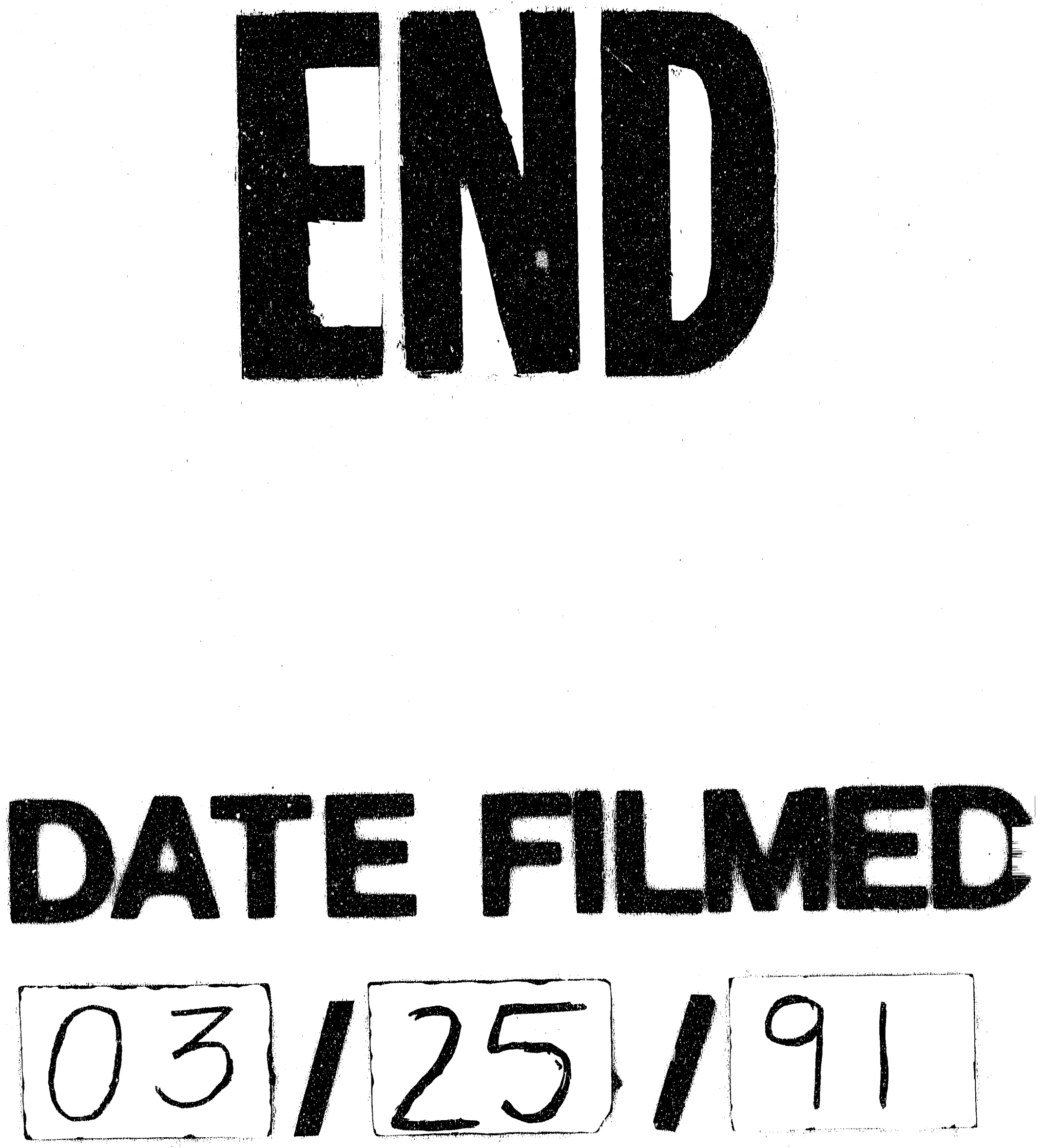
